\title{
LA REGIÓN DE METAGONIA, LA ESTRATEGIA DEFENSIVA DE ANÍBAL EN LIBIA Y EN IBERIA, Y LOS PRIMEROS TRATADOS ENTRE CARTAGO Y ROMA
}

\author{
THE REGION OF METAGONIA AND THE HANNIBAL'S DEFENSIVE STRATEGY IN LIBYA \\ AND IBERIA, AND THE FIRST TREATIES \\ BETWEEN CARTHAGE AND ROME
}

POR

\author{
Serafín Olcoz Yanguas* y Manuel Medrano Marqués**
}

\section{RESUMEN - ABSTRACT}

Presentamos una interpretación de la información epigráfica transmitida por Polibio de los bronces que contenían los primeros tratados entre Cartago y Roma, y el del templo de Hera Lacinia, acerca de la estrategia defensiva de Aníbal, que permite proponer una hipótesis para reconstruir la organización provincial de Cartago en Libia y en Iberia, en el marco de la lucha por la hegemonía en el Mediterráneo occidental. Esta propuesta también supone un punto de inflexión en el conocimiento de los pueblos prerromanos de la Península Ibérica y creemos que permitirá conocer mejor tanto la situación y organización de Cartago antes de la Segunda Guerra Púnica, como su posición frente a Roma y sus consecutivos procesos de conquista de Iberia.

We present an interpretation of the epigraphic information transmitted by Polybius about the bronzes containing the first treaties between Carthage and Rome, and the one of the Temple of Hera Lacinia about Hannibal's defensive strategy, which allows us to propose a hypothesis to reconstruct the provincial organization of Carthage in Libya and Iberia, as part of the struggle for hegemony in the western Mediterranean. This proposal also represents a turning point in the knowledge of the pre-Roman peoples of the Iberian Peninsula and we believe will provide a better understanding of the situation and organization of Carthage before the Second Punic War, its position in front of Rome and of their consecutive processes of the conquest of Iberia.

\section{Palabras Clave - Keywords}

Cartago; Roma; organización provincial; etnogegrafía ibérica; tratados.

Carthage; Rome; provincial organization; Iberian ethnogeography; treaties.

${ }^{*}$ Doctor por la Universidad de Zaragoza. Este trabajo se corresponde con una versión revisada y adaptada del Anexo I de la tesis doctoral leída en la Universidad de Zaragoza el 2 de abril de 2014 por Serafín Olcoz Yanguas, bajo la dirección de Manuel Medrano Marqués, solcoz@gmail.com.

** Profesor del Departamento de Ciencias de la Antigüedad de la Universidad de Zaragoza, Departamento de Ciencias de la Antigüedad. Facultad de Filosofía y Letras, medrano@unizar.es. 


\section{LOS PREPARATIVOS BÉLICOS DE ANÍBAL}

Hacia finales del otoño de $219^{1}$, tras haber conquistado Sagunto ${ }^{2}$, Aníbal se retiró a sus cuarteles de invierno, en la nueva Cartago ${ }^{3}$, y se centró en los preparativos para la campaña que iba a emprender contra Roma en la siguiente primavera. Una campaña con la que Aníbal iniciaría la Segunda Guerra Púnica tan pronto como cruzara con su ejército a la margen izquierda del río Ebro. Algo que entonces ya parecía inevitable tanto para romanos como cartagineses pues la causa del conflicto fue la lucha de ambos por la hegemonía del mundo conocido.

Sin embargo las cosas no ocurrieron exactamente como esperaba Aníbal pues, desde Roma, se le adelantaron enviando una delegación que acabó declarándole la guerra a la vieja Cartago tan sólo unas semanas antes de la fecha en la que él tenía previsto iniciar su campaña. Seguramente esta actividad diplomática formó parte del último intento de Roma por retrasar el inicio del conflicto a la vez que trataba de recuperar la perdida iniciativa al respecto, sin éxito en lo primero y siendo demasiado tarde para lo segundo, ya que lo que resultó de ella fue un mero cambio formal en la relación de ambas potencias mediterráneas. Pues la diferencia resultante consistió en que, para cuando Aníbal recibió de Cartago las noticias resultantes de este encuentro diplomático y las esperadas órdenes para proseguir con la prevista campaña contra Roma y se puso en marcha con su ejército, ya estaba inmerso en la recién declarada guerra. Más aún para cuando cruzó el fronterizo Ebro con su ejército y sojuzgó a los habitantes de la región que había entre este río, la costa mediterránea y los Pirineos. Por lo que esta acción bélica ya no fue el pretexto ni la causa que originó esta guerra sino parte de sus inicios.

Volviendo a los comienzos del invierno de 219-218, recordemos que Polibio 4 registró las tres líneas principales de su estrategia, escribiendo: Aníbal, que a la sazón se encontraba en sus cuarteles de invierno en Nueva Cartago, primero, dejó marchar a los iberos a sus respectivas ciudades con el propósito de tenerlos dispuestos y animosos para el futuro ${ }^{5}$; segundo, instruyó a su hermano Asdrúbal de la conducta que debía seguir no sólo en el gobierno y la autoridad de Iberia, sino también en los preparativos contra los romanos, caso de que él, en persona, permaneciera separado y, por último, tomó precauciones por la seguridad de los asuntos de Libia ${ }^{6}$. Esto último prueba que Aníbal era consciente de que lo más probable es que, en cuanto en Roma supieran que su ejército había cruzado el Ebro y que, de este modo, con él llevaba la guerra hacia la misma Italia, contraatacarían por su retaguardia para intentar dejarle aislado de ella y, por tanto, para disminuir su capacidad bélica y hacerle así más vulnerable o incluso como medio para acabar derrotándole en Italia. Así como que la guerra también repercutiría en la vieja Cartago si sus movimientos no eran lo suficientemente rápidos como para evitarlo y mantenerla focalizada en Italia.

1 Todas las fechas son a. C.

2 Sagunto (Valencia, Comunidad Valenciana).

3 Cartagena (Murcia).

4 En la citada tesis doctoral optamos por revisar las fuentes literarias más antiguas y cercanas a los acontecimientos analizados en su período de estudio, dedicado a la conquista romana de Celtiberia (219-167), principalmente las obras de Polibio y Tito Livio.

5 Livio relató la arenga con la que Aníbal, al comienzo del invierno de 219-218, despidió a los Hispanos hasta el comienzo de la primavera. Aunque cometió el error de añadir que, para entonces, Aníbal ya conocía el resultado de la reunión de la embajada romana en Cartago, Liv. XXI 21.1-8, que, como veremos, ocurrió a finales del invierno o en los primeros días de la primavera de 218. Confundiendo así, él o sus fuentes, el contenido de la arenga que Aníbal dio a los hispanos al comienzo del invierno, con la que también les dio al comienzo de la primavera y de la que Livio no dijo nada, y añadiendo los acontecimientos que ocurrieron hacia el comienzo de la primavera de 218 como si hubieran sucedido al principio del invierno anterior, Liv. XXI 21.9-13 y 22.1-5.

6 Plb. III 33.1-9. 
Centrémonos pues en esta tercera línea de la estrategia de Aníbal $^{7}$ y veamos qué información podemos extraer del relato acerca de cómo éste se preocupó de dejar bien organizada la defensa de los intereses de Cartago, tanto en la provincia cartaginesa de Iberia como en la de Libia, sabiendo que Polibio escribió: A tal efecto, con cálculo lleno de experiencia y de prudencia, hizo pasar soldados de Libia a Iberia y de Iberia a Libia , ligando lazos mutuos de lealtad entre uno y otro pueblo mediante tal intercambio, Plb. III 33.17.8-99. Para ello, contamos con la pormenorizada descripción que registró Polibio ${ }^{10} \mathrm{y}$ con la que Livio ${ }^{11}$ no sólo siguió el relato de éste con gran fidelidad sino que también comprobaremos que, algunas veces, lo reelaboró para ofrecer su propia versión, aportando algunos detalles o matices que nos van a ser de gran utilidad. Destacando que uno de los datos más interesantes de este relato es el de la descripción de la propia fuente utilizada por Polibio en esta ocasión pues, gracias a las explicaciones que dio sobre ella, ahora sabemos por qué el relato de este episodio fue tan detallado y específico, así como en qué condiciones se produjo.

El megalopolitano escribió: Y no hay por qué sorprenderse de la minuciosidad de esta enumeración que ofrecemos sobre las operaciones realizadas por Aníbal en Iberia, minuciosidad que dificilmente habría alcanzado un hombre que hubiera manejado, por sí, las acciones por separado ${ }^{12}$. Tampoco hay por qué imputarme de antemano que hemos procedido de modo semejante a aquellos historiadores que presentan sus embustes en forma digna de crédito. Nosotros hemos encontrado en el cabo Lacinio esta enumeración, consignada por Aníbal en una tablilla de bronce, cuando estuvo en estos parajes de Italia y hemos pensado, sin recelos, que tal tablilla, respecto a estas cuestiones, al menos, es digna de credibilidad. Por ello hemos decidido atenernos a este documento, Plb. III 33.17.1-8. Además y como ya señalara Domínguez $^{13}$, gracias a la información complementaria que aportó el patavino, sabemos algo más acerca de esta desaparecida placa de bronce que Aníbal mandó labrar y dedicar a la diosa Hera, escribiendo: Se propagó una epidemia causando parecidos estragos entre romanos y cartagineses, si bien al ejército cartaginés además de la enfermedad lo azotó también el hambre. Aníbal pasó el verano cerca del templo de Juno Lacinia y levantó alli un altar y lo dedicó con una gran inscripción grabada en caracteres púnicos y griegos refiriendo sus hazañas, Liv., XXVIII 46.15-16 ${ }^{14}$. Lo que nos permite disfrutar de los nuevos detalles acerca de la inscripción

7 A pesar del título de su trabajo, Fronda 2011, no contempló nada de esto, ni siquiera lo planteó, a la hora de revisar las tácticas, estrategia y geoestrategia de Aníbal.

8 Polibio identificó la clara diferencia existente entre ambas provincias cartaginesas estando Aníbal a cargo de la de Iberia y de la organización de la campaña contra Roma.

9 Véase una versión similar en Liv. XXI 21.11-12.

10 Plb. III 33.

11 Liv. XXI 21.9-13 y 22.1-4.

12 Polibio enfatizó cómo, a partir de la Segunda Guerra Púnica, los que habían sido escenarios bélicos aislados en diferentes zonas del Mediterráneo pasaron a estar interconectados y cómo la comprensión de tales sucesos requería de una doble perspectiva, o sea ir, desde los hechos particulares al todo y desde éste a lo singular, Plb. III 1.7, siguiendo el objetivo que declaró al escribir: En realidad, lo que me ha invitado y empujado a la empresa de esta historia, ha sido precisamente eso y con ello, también, el que ninguno de nuestro tiempo haya emprendido la concatenación de los acontecimientos en su conjunto: en tal caso habría puesto por mi parte mucho menos entusiasmo en mi tarea, Plb. I 4.2-3.

13 Domínguez 1995: 228.

14 Polibio aportó más detalles acerca del tipo de objeto en el que se encontraba esta inscripción y de la información aportada por ésta al recoger que, cuando Aníbal bajó de los Alpes: Sus tropas las constituía un contingente de doce mil infantes, supervivientes del ejército libio, y alrededor de ocho mil iberos, de una parte, y no más de seis mil jinetes en total, de otra, como el propio Aníbal hace saber sobre una columna, en Lacinio, que contiene el catálogo de sus fuerzas, Plb. III 56.4. Lástima que en esta ocasión Polibio no fuera tan cuidadoso al transcribir los detalles y en lugar de copiar la que debió de ser una pormenorizada relación de las tropas que llegaron a Italia con Aníbal, agrupó éstas en las dos categorías genéricas de libios e iberos, haciendo uso de la forma genérica con la que Polibio se refirió a las dos provincias cartaginesas y a los habitantes de éstas. 
bilingüe y del templo en el que ésta estuvo ${ }^{15}$, saber algo más de su contexto y datar también la fecha de esta inscripción en el verano de $205^{16}$. Pero antes de entrar en materia y aunque ahora parezca una digresión, creemos que es necesario realizar una revisión de lo que hasta ahora se conoce y lo que se puede conocer acerca de la región norteafricana de Metagonia. Pues veremos que a ella se hace referencia en la descripción que hizo Aníbal de su estrategia defensiva y que conocer esta información nos va a resultar de gran utilidad para comprender la propia estrategia y la distribución de los dominios cartagineses en las provincias de Libia y de Iberia, así como la interacción entre Cartago y la república de Roma desde los orígenes de ésta.

\section{METAGONIA EN LA OBRA DE POLIBIO Y EN LA VERSIÓN DE LIVIO}

Una de las últimas revisiones de las propuestas acerca de dónde pudo estar la región de Metagonia la realizó Gozalbes ${ }^{17}$, dando por buena la propuesta de Gsel1 ${ }^{18}$ acerca de que: el nombre de Metagonium aparecía con cierta frecuencia, desde época muy antigua, referido a unos puntos geográficos muy diversos. En todo caso, esos puntos estaban centrados en el considerable espacio costero entre la costa númida argelina hasta el Estrecho de Gibraltar ${ }^{19}$. Además Gozalbes, en busca de las huellas que los pueblos de la Península Ibérica y de otros lugares pudieron haber dejado en dicha Metagonia, revisó la noticia que había publicado García acerca del supuesto descubrimiento de la "Necrópolis ibérica de Orán", que resultó tratarse de una falsificación, y también citó que posteriormente lo había demostrado Santos pues aunque los restos eran efectivamente ibéricos, no procedían del norte de África sino de la zona alicantina $^{20}$. Finalmente tuvo en cuenta otro hallazgo más reciente, el de las monedas cartaginesas encontradas en los dragados del puerto de Melilla de 1953 y de 1981, y que, al parecer, procedían de un pecio que dató entre 220 y 210 , cuyos restos también aparecieron en la segunda ocasión, concluyendo con que era indudable que, por las fechas, y por las características del hallazgo, que se relaciona con los indígenas hispanos trasladados por Anibal a Matagonium en el 218 a. de C. De hecho, el hallazgo se encuentra fuera de contexto en esta región del Norte de África. Se inserta mucho más en el contexto de los hallazgos de la Península Ibérica. Estas monedas acuñadas en Cartago, estaban destinadas a pagar a los indigenas hispanos que habian sido alli asentados ${ }^{21}$.

Posteriormente y sin citar el trabajo de Gozalbes que acabamos de mencionar, Fernández et al. llegaron a conclusiones parecidas al tratar acerca de las citadas monedas púnicas del

15 Villar 1993a: 264 situó este templo: En un punto situado a seis millas de Crotona, en el promontorium Lacinium (Capo delle Colone), en el extremo sudoeste del Golfo de Tarento, siguiendo la detallada descripción aportada por Livio, quién concretó que el templo era más famoso que la propia ciudad, venerado en todos pueblos del contorno, Liv. XXIV 3.3-4. Lugar en el que también había situado el templo Díaz 1989: 59.

16 Liv. XXVIII 46.16. Quizá Aníbal hizo entonces una última y desesperada petición a la diosa Hera, ante la inminente pérdida de la provincia de Iberia en manos de los romanos, y esta inscripción pudo formar parte de la correspondiente ofrenda de todo lo que había venido realizando bajo su protección.

17 Gozalbes 2000: 117-120.

18 Gsell 1918: 156.

19 Gozalbes concretó: Este hecho le permitió concluir que la Metagonia correspondía con una parte de la costa argelina y con toda la costa marroquí del Mediterráneo, Gozalbes 2000: 117-118. Conclusión parecida a la que, sin explicar cómo, también había llegado Lazenby 1998: 32, por ejemplo, ubicando Metagonia en la parte este de la costa mediterránea de Marruecos.

20 Gozalbes 2000: 118-119, citó el trabajo de García 1954: 368-369 y la revisión que Santos 1983: 309-352 hizo de dichos restos arqueológicos ibéricos.

21 Gozalbes 2000: 120. 
pecio melillense ${ }^{22}$. Si bien éstos identificaron la región de Metagonia con la comprendida entre las ciudades del litoral del norte de África: Tánger (Marruecos) y Sirte (Libia), esto es, con lo que veremos que en realidad era todo el territorio que los cartagineses dominaban en el norte de África en época de Aníbal, concluyendo Fernández et al. con que Metagonia, el país al que se refiere Polibio, es, sin duda, el territorio comprendido entre Rus-addir y las Columnas de Hércules (Strab. III, 5, 5; Ptol. IV, 1, 5). El cabo Metagonion, fácilmente identificable con el Rus-addir de los púnicos, es el actual cabo Tres Forças (Strab. XVII, 3,6) (conocido localmente como Rus-er-Dir), en cuyo flanco oriental se encuentra la ciudad de Melilla, y fue llamado asi por los griegos por ser especialmente prominente, procediendo la voz ${ }^{23}$ de la expresión Metà to gònion akron que designa un país situado más allá de un cabo especialmente anguloso o pronunciado, de ahi precisamente que Metagonia sea el territorio que se encuentra más allá de dicho accidente geográfico y que sus habitantes sean señalados artificiosamente como metagonitas por Estrabón y Ptolomeo cuando ninguna tribu de la región portaba este nombre ${ }^{24}$. A pesar de señalar también que en la época cartaginesa el subsuelo melillense no ha ofrecido ningún dato concreto de tipo arqueológico, por ello no sólo es importante este hallazgo monetario sino el estudio y análisis de la madera y los clavos que según la breve referencia del profesor Manuel Martín Bueno a la cuestión, nos hallamos ante los restos de un barco cartaginés hundido y que "revela la importancia y utilización de aquel puerto ya en ese momento, lógico por su emplazamiento y las relaciones con la costa peninsular" 25 , no dudaron en identificar a Tánger y Melilla como dos de las ciudades de mayor importancia estratégica y portuaria durante la Segunda Guerra Púnica, señalando a esta última como el enlace entre las dos Cartago. Además, acabaron datando las monedas con el momento más álgido y crítico de la Segunda Guerra Púnica, cuando en Melilla (Metagonium) o en sus inmediaciones, se encontraban acantonados los contingentes de tropas de mercenarios procedentes de diferentes puntos de la Península y lógicamente demandaba un alto numerario para sus transacciones cotidianas $^{26}$.

Más recientemente y para finalizar ya esta breve recensión, queremos citar la existencia de trabajos en los que se ha tratado este episodio de los preliminares de la Segunda Guerra Púnica pero en los que ni siquiera se ha entrado a opinar acerca del hipotético lugar del norte de África en el que pudo estar la región de Metagonia ${ }^{27}$. Lo que pensamos que muestra que, o bien se cree que ya no se puede ubicar mejor dónde estuvo esta región, o que ni siquiera las propuestas conocidas eran o son lo suficientemente seguras como para señalarlas a la hora de situarla. De ahí que creamos conveniente insistir en ello, aplicando el método de complementar la revisión del relato de Polibio con la información aportada por el de Livio pues creemos que conocer dónde estuvo la región de Metagonia va a resultar clave para comprender la estrategia defensiva de Aníbal. Aunque hasta ahora no se haya considerado así y el conocimiento de su localización haya sido algo a lo que no se le ha dado gran importancia.

22 Fernández et al. 2001-2002: 190-192. Por otra parte, estos autores cometieron el error de considerar que el Tratado del Ebro data de 221 cuando en realidad es conocido que fue alcanzado entre el Senado de Roma y Asdrúbal, en Cartagena, entre el otoño de 226 y la primavera de 225, véase Sancho 1976: 76, 83-93 y 110, a la hora de datar las monedas púnicas halladas en Melilla, Fernández et al. 2001-2002: 189.

23 Citando la edición del tomo V de la Historia Natural, de Desanges 1980: 188 pero sin advertir Fernández et al. que, por ejemplo, Plinio se refirió como metagonitas a los habitantes de Numidia occidental, Plin. Nat. His. V 22.

24 Fernández et al. 2001-2002: 191.

25 Fernández et al. 2001-2002: 192.

26 Fernández et al. 2001-2002: 192 y Moret 2003: 294-298. Obsérvese que éstos también calificaron de mercenarios a las tropas desplazadas por Aníbal a Libia en el invierno de 219-218, cuando no fue así.

27 Pérez 2003 y García-Gelabert 2005. 
Por lo que es hora ya de que entremos en materia y vayamos al apartado de este relato en el que Polibio citó a la región de Metagonia escribiendo: Pues bien, de los mencionados pueblos [procedentes de la provincia de Iberia], a la mayor parte la acuarteló en la región de Metagonia de Libia y a algunos en la misma Cartago. Y desde las ciudades de la denominada Metagonia envió otros infantes a Cartago, unos cuatro mil, con la misión de servir, a la vez, de rehenes y de reserva, Plb. III 33.12-14. Mientras que, en la correspondiente reelaboración de Livio, nos llama la atención el hecho de que éste no citara para nada a la región de Metagonia pues registró: A estas tropas [de la provincia de Iberia] les da orden de servir en parte en la guarnición de Cartago y en parte las distribuye por África. Al mismo tiempo, después de enviar reclutadores a las ciudades [¿de Metagonia?], ordena que los cuatro mil jóvenes escogidos reclutados sean conducidos a Cartago como guarnición a la vez que como rehenes, Liv. XXI $21.13^{28}$. A primera vista podría parecer que Livio cometió una imprecisión o incluso un error ya que, a pesar de lo puntilloso que demuestra ser en otras ocasiones, en ésta parece que no especificó en qué ciudades se hizo el reclutamiento ${ }^{29}$. Pero veremos que no es el caso y que la aparente imprecisión se debe a una deficiencia de la traducción y que en ella está la clave del misterio sobre Metagonia. Para ello tengamos en cuenta que la versión de Livio no es una copia literal en el orden en que figuran los puntos expuestos por Polibio y que, por tanto, es de esperar que parte de la información que éste puso en un párrafo, Livio la incluyera en otro. De ahí que sólo después de haber leído completamente ambos textos es cuando se pueden comparar las informaciones aportadas por cada uno de ellos. Por eso veamos ahora esta otra parte de la información que ya hemos visto en la versión de Polibio: A continuación, [Aníbal] preocupándose al mismo tiempo de la ofensiva y la defensiva bélica, no fuera a ocurrir que, mientras él se dirigía a Italia por tierra a través de Hispania y de la Galia, quedase África desguarnecida y con el flanco descubierto por la parte de Sicilia para los romanos, decidió asegurarla con una sólida guarnición, Liv. XXI 21.10-1130. En ella observamos que el patavino completó la descripción de la maniobra defensiva de Aníbal con una información que nos permite deducir que la región del norte de África a la que Polibio se refería como Metagonia es precisamente la que se encontraba situada enfrente de la costa meridional de Sicilia. Es más creemos que Metagonia, siguiendo su etimología, no era el topónimo de una región particular sino que se trata de una forma genérica de designar a un territorio situado más allá de un promontorio costero cuya localización depende del contexto concreto del texto donde se mencione cada Metagonia y que, en el caso que nos ocupa, veremos que hace referencia literalmente a las ciudades de la región que se encontraban más allá del promontorio situado al Oriente de Cartago, que es el Cabo Bon (Túnez) ${ }^{31}$, o sea al Oriente de éste. Por lo que es un craso error el

28 Traducción de Villar que coincide con la versión latina de Herrero 1985: 85-86, en la que se puede apreciar que Livio omitió la referencia explícita a Metagonia y que si se hubiera tenido en cuenta el paralelismo de este texto con el de Polibio, una traducción más exacta creemos que habría sido: A estas tropas les da orden de servir en parte en la guarnición de Cartago y en parte las distribuye por África. Del mismo modo, después de enviar reclutadores a las ciudades de África [en realidad o concretamente a las ciudades de Metagonia], ordena que los cuatro mil jóvenes escogidos [que alli fueron] reclutados sean conducidos a Cartago como guarnición a la vez que como rehenes.

29 Imprecisión o error aparente que no fue detectado por Gozalbes 2000: 117 ya que éste consideró que la de Livio se trataba sencillamente de una versión alternativa a la de Polibio, en la que aquél había cambiado la forma en que Aníbal llevó a cabo su estrategia defensiva.

30 Estrategia que Polibio registró que tenían previsto aplicar los romanos ya que por eso habian enviado a uno de los cónsules a Libia con intención de poner sitio a Cartago y al otro a Iberia donde debía hacer la guerra a Aníbal, Plb. III 61.8 .

31 Es el mayor de los dos promontorios que defienden Cartago, Plb. I/2 42.6-7, y está situado en el extremo oriental de su bahía. A este cabo también hizo referencia Polibio en un episodio de la Primera Guerra Púnica (264-241), datado en 256, citándolo como cabo Hermeo o de Hermes, Plb. I/1 29.2 y Plb. I/2 36.11. Seguramente porque en uno de sus montes existió un templo dedicado al dios al que los romanos se referían como Mercurio. Lo que ayuda a identificarlo con el 
intento que se ha venido haciendo de unificar todas las referencias metagónicas que se citan en las obras de la Antigüedad, como si se trataran de menciones a un único y mismo lugar.

Para identificar el cabo o promontorio más allá del cual se encontraba la Metagonia que se menciona en el bronce del templo de Hera Lacinia, acudimos de nuevo a Polibio y, concretamente, a la interpretación que expuso como resultado de la autopsia que hizo de las placas de bronce en las que estaban los tres tratados más antiguos entre romanos y cartagineses ${ }^{32}$. En ellos observamos que se cita o utiliza un cabo, el correspondiente al promontorio Hermoso, en los dos primeros para delimitar el inicio de la zona cartaginesa en las cercanías de Cartago por la que los romanos aceptaron abstenerse de navegar excepto si eran conducidos a ella por fuerza de causa mayor y, aún así, que debían hacerlo entonces con restricciones ${ }^{33}$. Explicando Polibio la razón que él creyó que subyacía en la delimitación de esta zona de exclusión, situada al este de dicho promontorio Hermoso, diciendo: Más allá del cual los cartagineses se oponen a que los romanos naveguen hacia el mediodía con naves de guerra, porque, a mi parecer, no quieren que aquéllos conozcan la región de Bisatis, ni la de Sirte Menor, lugares que, por la fertilidad de sus campos, llaman precisamente Emporios, Plb. III 23.2-3. Por lo que no cabe duda de que Polibio identificó el promontorio Hermoso con el de Hermes, esto es, con el cabo Bon $^{34}$. Así como que también interpretó que la zona vedada entonces a Roma era la región

promontorio de Mercurio que Livio citó al describir la llegada a Cartago de Publio Cornelio Escipión (que sería conocido como El Africano), en 204, Liv. XXIX 27.8. Si bien el patavino también escribió que este desembarco acaeció en el promontorio Pulcro, que se corresponde con el que también citó como promontorio de Apolo o actual cabo Farina (Túnez), siendo precisamente éste el otro promontorio que está situado en el extremo occidental de la bahía de Cartago, Liv. XXIX 27.8, 12-13 y 34.3, y XXX 24.8-9. Morillo 1993: 384-385 contabilizó este campamento romano entre los más destacados de esta guerra, datando erróneamente la conquista de Cartagena en 210.

32 Polibio, revisó las relaciones jurídicas entre romanos y cartagineses, desde los orígenes de la república de Roma pues, con una triple data, fechó el primero de estos tratados en este momento, hacia 508, Plb. III 21.10 y 22.1-2. Transcribiendo una versión elaborada de este primer tratado, Plb. III 22.4-13, y añadiendo una aclaración acerca de con qué promontorio fronterizo debía identificarse el que se cita en los dos primeros tratados con el apelativo de Hermoso, Plb. III 23. Pues, debido a la evolución de la lengua y a pesar de exponer que contó con la ayuda de los romanos más inteligentes para realizar la autopsia de las placas de bronce en las que se encontraba el primer tratado, escribió que incluso éstos $a$ duras penas y después de esforzada aplicación, logran comprender algunos lugares, Plb. III 22.3-4 y 26.1-2. Así como también transcribió el segundo tratado, Plb. III 24.3-13, con los correspondientes comentarios, Plb. III 24.1-3 y 24.14-16. Incluyendo las referencias a las ciudades costeras del Lacio que debían ser respetadas por los cartagineses, en su calidad de aliadas de Roma y, por tanto, cubiertas por la cláusula inicial de amistad del tratado. Señalando que Polibio no cometió ningún error en su comentario al respecto aunque en este segundo tratado no se citara a estas ciudades explícitamente y sí se hiciera así en el primero ya que dicho comentario era consistente con el contenido del segundo tratado. Acuerdo que, aunque no fue fechado por Polibio, se considera que data de 348, incluyendo entre quienes así han procedido el propio trabajo de Espada 2013 y todos los que revisó éste. Del mismo modo que Polibio también añadió las cláusulas del tercer tratado que no estaban ya incluidas en los dos anteriores, como él mismo expuso, Plb. III 25, antes de criticar la falsedad y falta de método y de fuentes en las que apoyarse, que tenía la obra que cuestionó de Filino, añadiendo que no sólo no existió el tratado que éste mencionaba sino que dicho supuesto tratado, de haber existido, contradiría los que él acababa de transcribir así como que éstos eran desconocidos por Filino y por la mayoría de los romanos, Plb. III 26. Todo ello a pesar de que las placas de bronce de esos tres primeros tratados aún podían verse, en vida de Polibio, en el tesoro de los ediles, cerca de Júpiter Capitolino, Plb. III 26.1-2. Siendo esta referencia a la obra de Filino otro punto que también sigue generando debate, como recogió Hoyos 2011: 131. A pesar de la claridad de los argumentos de Polibio, seguramente porque éstos no se leen con la atención y se malinterpretan, como hizo Scardigli 2011: 33. Finalmente, nos queda añadir que Polibio completó su recensión de los tres tratados más antiguos, haciendo mención de los juramentos con los que fueron avalados, Plb. III 25.6-9.

33 Estas limitaciones se recogen en ambos tratados, Plb. III 22.5-10 y 24.4.

34 La aclaración de Polibio determina la identificación del promontorio Hermoso con el cabo Bon y la zona vedada a Roma con la situada al Oriente de éste. Si bien esta identificación sigue generando gran controversia, como puede verse en Scardigli 2011: 30 o en Espada 2013: 239-245 y 270. No porque no esté claro que los emporios citados por Polibio se encontraban más allá del cabo Bon y que no podían estarlo más allá del cabo Farina pues, en este caso, la limitación impuesta a Roma en el primer tratado excluiría el acceso comercial de ésta a Cartago y eso es incompatible con lo expuesto en el segundo tratado, en el que sigue vigente la zona vedada a Roma en el primero, Plb. III 24.4 y 12, como señalara 
situada más allá y al Oriente de éste. Una región que veremos que se corresponde con el extremo occidental de la Metagonia o, literalmente, la región más allá del promontorio que aparece citada en el bronce del templo de Hera Lacinia, que mandó labrar Aníbal.

Por otra parte, sabemos que Polibio también describió los límites de los dominios de Cartago, en ambas márgenes del Mediterráneo, una vez que Aníbal hubo cruzado los Pirineos por el paso de Colliure, a finales del verano de 218, diciendo: $Y$ en efecto, los cartagineses, en este tiempo, eran dueños en lo tocante a Libia, de todas las partes que miran al mar interior [el Mediterráneo], desde los altares de Fileno, que están situados en la Sirte Mayor, hasta las Columnas de Hércules ${ }^{35}$. Por lo que creemos que el extremo oriental de la región de Metagonia correspondería a los citados altares de Fileno en la Gran $\operatorname{Sirte}^{36}$, y que fue en las ciudades metagonitas en las que entonces se reubicaron aquellos rehenes-refuerzos procedentes de la provincia de Iberia que no lo hicieron en Cartago ${ }^{37}$. Así como que estas ciudades fueron las que entonces aportaron alrededor de 4.000 infantes a la guarnición de ésta. En definitiva que las ciudades de la región de Metagonia a la que se refirió Polibio fueron las que actualmente hay entre el cabo Bon y el extremo oriental del golfo de Sidra.

Esta deducción no sólo echa por tierra las propuestas que hasta ahora se han venido haciendo acerca de esta Metagonia sino que veremos que nos permite darle al párrafo de Polibio en el que figura el sentido que tiene, tanto en el propio párrafo como a toda la estrategia de Aníbal. Pues teniendo en cuenta que el contingente reclutado en esas ciudades no eran mercenarios, ya que Polibio indicó claramente su doble carácter: como refuerzo del lugar de destino pero también como rehenes para que en sus lugares de procedencia se cumpliera con los pactos acordados con Aníbal, podemos deducir que estas ciudades metagonitas estaban supeditadas política, militar y administrativamente a Cartago. Lo que nos da pie a interpretar de forma novedosa la información que Polibio recogió acerca del bronce del templo de Hera Lacinia, así como a relacionar ésta con la defensa que Cartago ya habría hecho de este territorio desde el primer tratado que acordó con Roma, según la interpretación que hemos visto que Polibio hizo de éste, o puede que incluso desde antes.

Sin embargo, también queremos destacar que nuestra aproximación no es completamente nueva, aunque sí lo sean el enfoque y las conclusiones a las que nos va a permitir llegar, pues en cierto modo vamos a recuperar la idea que llevó a Pérez a considerar que el análisis de parte del contenido del citado bronce podía proporcionar alguna perspectiva acerca de la adminis-

\footnotetext{
Moret 2002: 268, pues no hay duda de ello y así se recoge tanto en las revisiones de Scardigli 2011:30 o Espada 2013: 239-245 y 270. Si bien Scardigli añadió que Polibio se equivocó al identificar la zona vedada a Roma pues ésta sería la situada al oeste del cabo y no al éste como interpretó el megalopolitano. Algo que, como acabamos de ver, es incompatible con el segundo tratado entre Roma y Cartago. Mientras que la otra opción citada en la revisión que hizo Scardigli, la que considera que Polibio en lo que se equivocó fue al identificar el promontorio Hermoso y que éste se correspondía con el cabo Farina y, por tanto, que la zona de exclusión para Roma debería de ser la situada al oeste de éste, tiene a su favor el que, como hemos visto, este cabo se conocía como promontorio de Apolo y que, además, Livio lo citó también como de Pulcro, en latín. Lo que algunos han creído que permitiría identificarlo con el Hermoso, citado en griego por Polibio. Algo que no tiene por qué ser así, como ya expusiera Desanges 1963 y 1990, sin necesidad de plantear el argumento que anunció pero no llegó a publicar Pena 1976-1978: 516-518 para demostrar el supuesto error de Livio que también creyó que podría existir aquí. No obstante, de Hoz 2010:228, que también aceptó la identificación del promontorio Hermoso con el cabo Bon, señaló acertadamente que quienes aboguen por considerar que Polibio erró, tendrán que demostrarlo.

35 Concluyendo este párrafo con que: Y de otro lado, una vez que aquéllos [los cartagineses] hubieron franqueado el estrecho en las Columnas de Hércules, igualmente dominaron también toda Iberia hasta los acantilados rocosos que sobre nuestro mar constituyen el extremo de los montes Pirineos, límites de iberos y galos, Plb. III 39.2-5.

36 Sal. 19.3 y los comentarios de la editora Carrera 2001: 281.

37 Los dominios de la ciudad de Cartago abarcaban un territorio alrededor de ella en el que se encontraban varias ciudades que eran cabezas de cada uno de los distritos en los que se organizaba administrativamente este ámbito. Véase Picard 1966.
} 


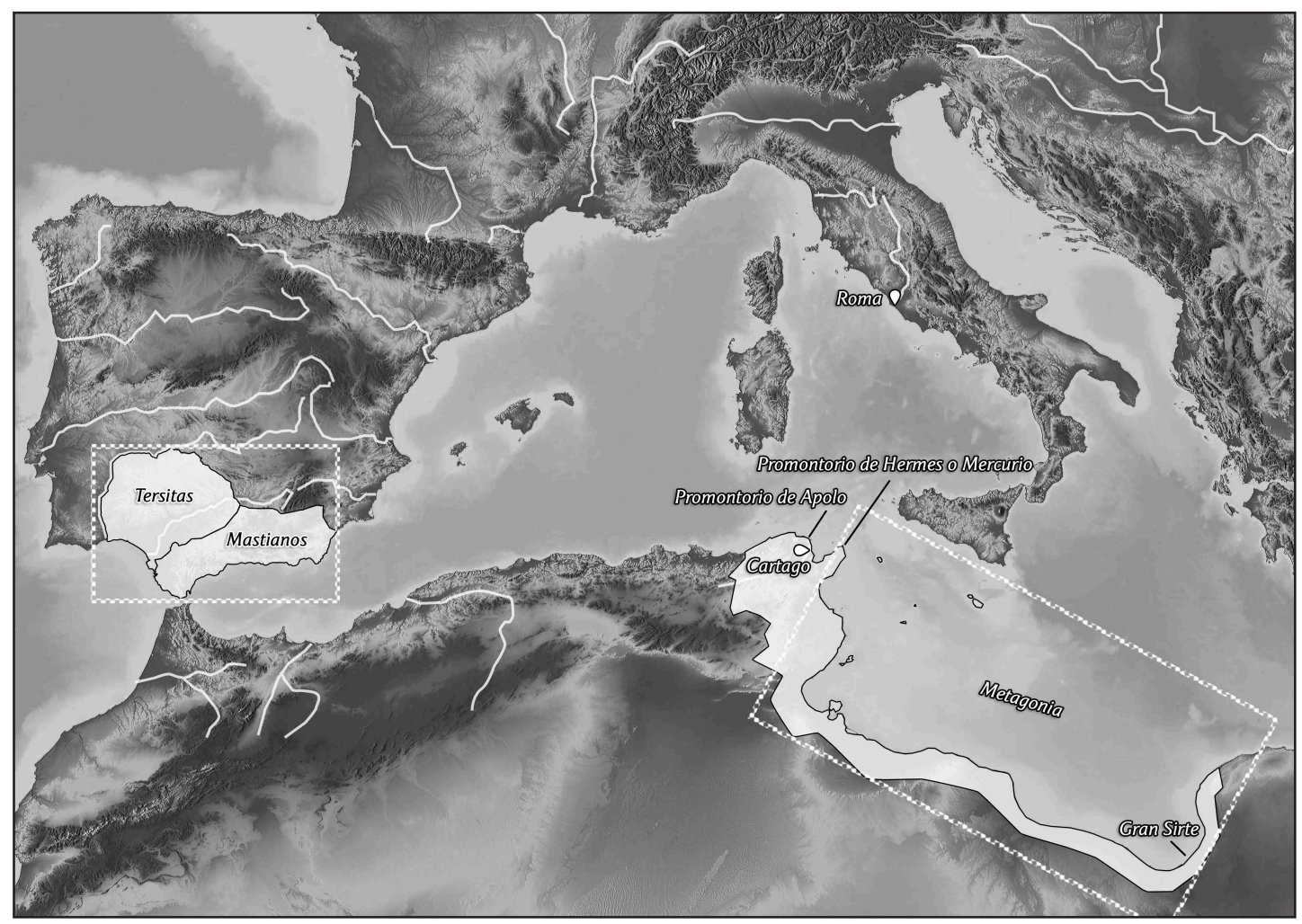

Figura 1. Regiones vedadas a Roma por Cartago.

tración territorial de los dominios cartagineses en Iberia ${ }^{38}$. Sólo que, en lugar de hacerlo como lo hizo él, vamos a abordar su hermenéutica de modo global, teniendo en cuenta que ese texto reflejaba de forma pormenorizada la estrategia de Aníbal para defender todos los territorios que entonces dependían de Cartago, ante la posible reacción que Roma podía emprender en cualquiera de ellos, quizá hasta de forma simultánea, una vez que tuviera conocimiento de que su expedición había cruzado ya el Ebro. Algo que no era una mera suposición previsora de Aníbal, pues Livio recogió que, antes incluso de enviar la citada embajada que declaró la guerra a Cartago, en Roma: Ya se habian designado con anterioridad los campos de operaciones de los cónsules; se les pidió entonces que los echaran a suertes. A [Publio] Cornelio [Escipión] le tocó Hispania, a [Tiberio] Sempronio [Longo] África junto con Sicilia, Liv. XXI 17.1-2 ${ }^{39}$. Por lo que Aníbal no hizo otra cosa con su estrategia defensiva que anticiparse a la de Roma.

En definitiva, nos proponemos interpretar todos los datos del citado bronce del templo de Hera Lacinia para averiguar cómo pensaba Aníbal que debían protegerse todas las regiones dominadas entonces por Cartago, al margen del propio territorio conexo a esta ciudad y a cuya administración ya hemos aludido, y de ello deducir cuáles fueron las regiones supeditadas

38 Pérez 2003: 27-28. Además, en contra de lo expuesto por Polibio y Livio, Pérez 2003: 29 supuso una asignación diferente para las tropas que pasaron de la provincia cartaginesa de Libia a la de Iberia y las relacionó con episodios de la Segunda Guerra Púnica en los que no hay razón para pensar que intervinieran.

39 Una información que previamente había recogido Polibio, escribiendo: Los romanos enviaron a Tiberio Sempronio a África con una armada y a Publio Cornelio a España, Plb V 1.4-5. 
a ésta que sustentaron dicha estrategia, y por qué fueron sólo esas y no incluyó a otras. No dando por sentado, como hizo Pérez, que Cartago constaba entonces de dos provincias: Iberia y Libia, y que esta última carecía de organización administrativa debido al carácter nómada de los pueblos que habitaban en ella ${ }^{40}$, así como tampoco que, a su vez, la provincia de Iberia estuviera dividida en las regiones que Pérez propuso ni en los razonamientos en los que se basó para ello. De paso, comprobaremos que la interpretación polibiana de la identificación del promontorio Hermoso con el cabo Bon no sólo fue correcta, en contra de lo que se viene creyendo actualmente, sino que además es la única consistente con el resto de la información arqueológica que manejó de primera mano. Con lo que además se clarifican definitivamente gran número de las dudas que han perdurado acerca de la interpretación de los primeros tratados entre Cartago y Roma, y de las implicaciones que esto tiene.

\section{LA ORGANIZACIÓN REGIONAL DE CARTAGO EN LIBIA}

Una vez visto que la organización de las ciudades situadas en los dominios orientales de Cartago nos permite suponer que Metagonia fue una de sus regiones en Libia, vamos a considerar también que no fue casual el hecho de que Aníbal hiciera pivotar la defensa de los territorios cartagineses distinguiendo las operaciones a realizar en Cartago, de las que había que emprender en su región oriental o de la que organizó para las que veremos que fueron sus cuatro regiones occidentales en Libia.

En primer lugar, vamos a revisar las referencias a los territorios que tuvo Cartago por el oeste de Libia aprovechando que Polibio, al acabar de describir la estrategia de Aníbal y comenzar a detallar las tropas que le dejó a su hermano Asdrúbal, también escribió: De otra parte, en Iberia [Aníbal] dejó a su hermano Asdrúbal cincuenta quinquerremes, dos cuatrirremes y cinco trirremes, de los que treinta y dos quinquerremes y los cinco trirremes disponían de sus dotaciones. Igualmente, le dejó cuatrocientos cincuenta jinetes de libiofenicios y libios, trescientos de [i] lergetas y mil ochocientos de entre los númidas, esto es, masilios, masesilios, macceos y mauritanos, los de la costa del Océano. Y como soldados de a pie, once mil ochocientos cincuenta libios, trescientos ligures, quinientos baleares, asi como veintiún elefantes, Plb. III 33.15-16. Para interpretar este texto, nuevamente nos apoyamos en que Livio lo reelaboró, juntando lo expuesto en él con parte de otro párrafo que ya hemos visto antes y escribiendo: Pensando que tampoco Hispania debía quedar descuidada, y por ello mayor razón porque no era desconocedor de que la habian recorrido los embajadores romanos para atraerse la voluntad de sus jefes, se la asigna como campo de operaciones a su hermano Asdrúbal, hombre activo y le da seguridad con refuerzos sobre todo africanos ${ }^{41}$ : once mil ochocientos cincuenta africanos de infantería, trescientos ligures, quinientos baleares. A estas fuerzas auxiliares de infantería se sumaron cuatrocientos cincuenta jinetes libiofenicios, mezcla este contingente de cartagineses

\footnotetext{
40 Seguramente influido por Plinio, que escribió que a los habitantes de Numidia se les denominaba nómadas debido a que trasladaban sus casas en busca de pastos, Plin. Nat. His. V 22.

41 Como ejemplo del erróneo y superficial enfoque que, en general, se ha venido aplicando a este texto, sirva la cita al trabajo de Cruz 2003: 194, en el que creyó que estas tropas fueron destinadas a Italia para mostrar las diferencias con la aproximación que estamos siguiendo.
} 
y africanos ${ }^{42}$, y unos mil ochocientos númidas ${ }^{43}$ y moros, que habitan a la orilla del océano, más un reducido contingente de trescientos jinetes de ilergetes ${ }^{44}$ procedentes de Hispania; y para que no faltase ningún tipo de apoyo terrestre, veintiún elefantes. Además, para proteger la costa, pues cabía pensar que los romanos desarrollarían las operaciones bélicas, también entonces, en el terreno en que habian salido victoriosos, se le asigna una flota compuesta por cincuenta quinquerremes, dos cuatrirremes y cinco trirremes; pero utilizables y equipadas con sus remeros, habia treinta y dos quinquerremes y las cinco trirremes ${ }^{45}$. Pues, gracias a esta reelaboración de Livio podemos interpretar mejor el texto de Polibio y ver que los dos primeros pueblos norteafricanos citados por éste, en orden de este a oeste, corresponden a los dos reinos númidas que fueron unificados por Masinisa, al final de la Segunda Guerra Púnica. Tal como se ha venido haciendo al situar a los masilios en un territorio que estuvo entre lo que hoy sería el este de Argelia y el oeste de Túnez, y a los masesilios, vecinos de éstos, en el oeste de Argelia, lindando ya con el de los mauritanos ${ }^{46}$. Mientras que la referencia a los moros que citó Livio, englobando con ella a los otros dos pueblos enumerados por Polibio e identificándolos con los habitantes de la Mauritania existente en la época del patavino, nos permite sugerir que los territorios de aquellos otros dos pueblos pudieron ser los antecedentes de los que, posteriormente y siguiendo la mencionada orientación, dieron lugar a las provincias romanas de Mauritania Cesariana y Tingitana, respectivamente, en la época del emperador Claudio ${ }^{47}$.

42 En la obra de Livio se observa que algunos pueblos, cuando constituían una coalición, solían formar en el orden de batalla por bloques separados para cada uno de ellos, de lo que se podría deducir que la explicación que en esta ocasión dio Livio acerca de los jinetes libiofenicios hace referencia a una agrupación de jinetes fenicios o, mejor dicho, púnicos, y de jinetes africanos o libios. Por su parte, Domínguez 1995: 226-227, interpretó esta aclaración de Livio pensando que por libiofenicios se hacía referencia a un pueblo cuyo origen fuera la mezcla de libios y fenicios, basándose en Diod. XX 55 y citando también como ejemplo de su propuesta la explicación dada por Diodoro de Sicilia, Diod. V 33 acerca del origen de los celtíberos, como descendientes de celtas y de iberos, comparable a la utilización de libiofenicios que hizo Livio en este episodio. No obstante, comparando la versión de Livio con la de Polibio, observamos que éste citó un contingente de 450 jinetes libiofenicios y libios, por lo que creemos que cuando Livio intentó aclarar la composición de estos jinetes, al precisar que, a su vez, los libiofenicios eran una mezcla de púnicos y libios (Libyphoenices, mixtum Punicum Afris genus, Herrero 1985: 86) ya no le hizo falta detallar que entre los jinetes había también libios, pues éstos ya los consideró incluidos entre los propios libiofenicios, perdiendo así el detalle que aportó Polibio acerca de que entre los jinetes hubo libios y también libiofenicios.

43 Aunque Livio, en esta ocasión, no distinguió entre los dos pueblos númidas involucrados, sí que más tarde citó al de los masesilios como los masesulios, pueblo que limita con los moros, miran hacia Hispania, más o menos hacia donde queda Cartagena, Liv. XXVIII 17.5-6, aliados o dependientes de los cartagineses pero a los que Publio Cornelio Escipión, hijo, tras la conquista de esta ciudad, visitó a su rey, Sífax, a la vez que lo hacía Asdrúbal, para que se pasaran al bando romano, Liv. XXVIII 17.4-16 y 18. Livio también explicó cómo había evolucionado el reino de los otros númidas: los mesulios, contando con la ayuda de los moros, aunque sin hacer ninguna distinción entre éstos, y de cómo dichos mesulios dejaron a los cartagineses para ser aliados o dependientes de los romanos, una vez que Asdrúbal había puesto en su contra a los masesulios de Sífax. Lo que, al final, condujo a que el mesulio Masinisa, al aliarse o someterse a Publio, una vez que éste desembarcó en la bahía de Cartago, para conquistar esta ciudad, acabó por hacerse con ambos reinos númidas y otras prebendas con las que le recompensó Publio después de lograr la victoria de Roma en la Segunda Guerra Púnica, Liv. XXIX 28-35, XXX y XXXVII 25.9-10.

44 La referencia a los ilergetes es similar a la de los lergetas que menciona Polibio, de ahí que se identifique a ambos con el pueblo ibero del norte del Ebro, en el noreste peninsular.

45 Liv. XXI 22.1-4.

46 Por ejemplo, Pérez llamó la atención acerca de que el nombre de númidas procede de la condición de nómadas que tenían sus integrantes norteafricanos, Pérez 2003: 19. Siguiendo la tradición de los escritores que, según Prados, confundió el nombre de los númidas con el adjetivo nómadas. Aunque según las hipótesis más tradicionales algunas tribus nómadas situadas al sur de Numidia acabaron siendo incorporadas a este reino en la época del citado rey Masinisa. Prados 2008: 41-43.

47 Espinosa 2004: 148 y Gozalbes 2010: 520. Véase el mapa del norte de África, Kiepert 1902. 


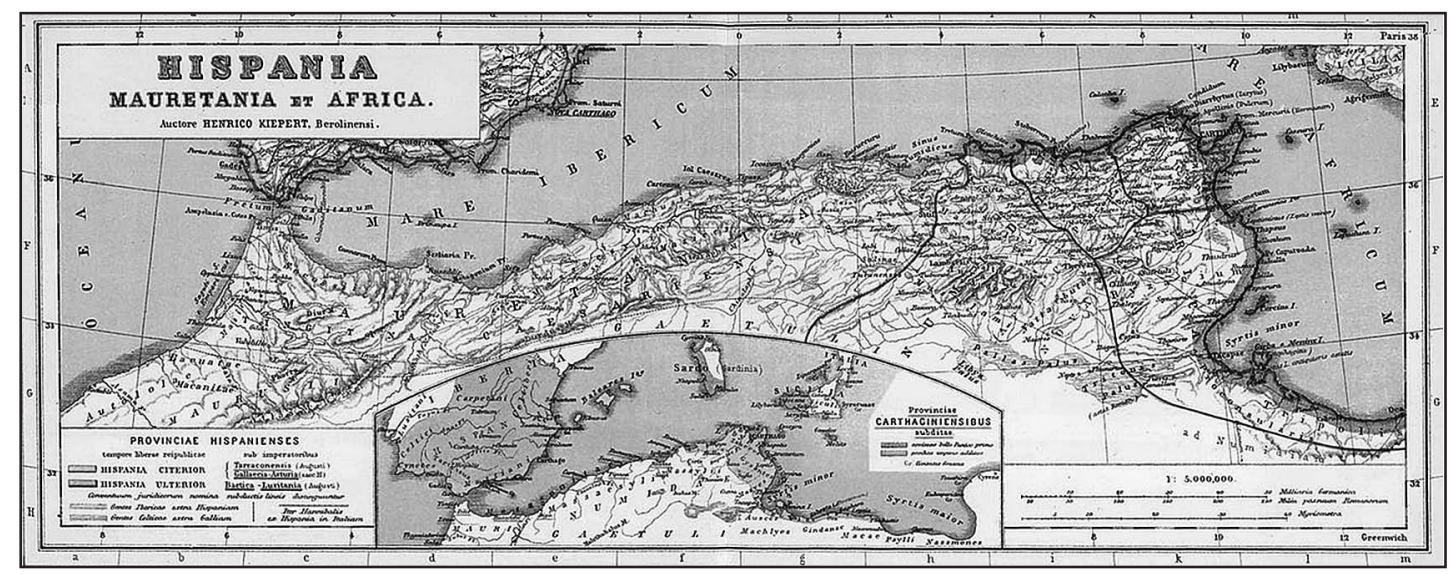

Figura 2. Norte de África, según H. Kiepert.

Visto lo cual, creemos que Cartago, además de administrar su propio territorio por medio de los distritos asociados a las ciudades que en él ejercían como cabeza de los mismos ${ }^{48}$, controlaba cinco regiones en Libia: una por el este, compuesta por las ciudades de la región de Metagonia situadas más allá del promontorio Hermoso o cabo Bon $^{49}$, y cuatro regiones númidas por el oeste: masilios, masesilios, macceos y mauritanos. Siendo el océano Atlántico el límite occidental de la franja costera de Libia en la que se encontraban todos estos dominios de Cartago, mientras que el oriental era su antigua frontera con Egipto, en la Gran Sirte. Así como por el norte estaba el mar Mediterráneo y por el sur tanto la cordillera del Atlas como el desierto del Sáhara. Por lo que no hay duda de que Aníbal se aseguró la defensa de estas cinco regiones por medio de su estrategia de intercambio de tropas-rehenes, destacando que, en el caso de Metagonia y por ser ésta la parte más expuesta a un ataque desde Roma, dada su cercanía a Sicilia, también hizo una importante leva destinada a Cartago. No sólo porque ésta era lo que mejor había que defender en esa área de Libia sino porque debía asegurarse de que las ciudades cercanas a las playas en las que previsiblemente desembarcarían los romanos le eran fieles a Cartago y estarían dispuestas a soportar el ataque de Roma, como primera línea de defensa de aquélla. Otro motivo más para justificar por qué habíamos dicho que era clave conocer la ubicación de Metagonia para comprender la estrategia defensiva de Aníbal y para entender los primeros tratados entre Cartago y Roma.

Dado que Pérez señaló que, según González, los cartagineses consideraron los territorios conquistados a los autóctonos como de su propiedad y recuerda la inexistencia de documenta-

48 Picard 1966 estudió la organización administrativa en la que se dividían los distritos asociados a las ciudades existentes en el territorio dominado directamente por Cartago, ciudades que serían así una especie de cabezas de distrito o prafecti pagi, como también señaló Pérez 2003: 17, citando a éste, al plantearse que esta forma de gestión administrativa sería comparable respecto a la de la "provincia ibera" de Cartago, asumiendo que la otra provincia de ésta en Libia era la del propio territorio de Cartago estudiado por Picard. Suposición que ahora se ve que carece de soporte, tras lo expuesto acerca de las ciudades de Metagonia o, si se prefiere, de la región de "Libia oriental" de Cartago, al margen de las ciudades del propio territorio de ésta. En cualquier caso, es interesante destacar que Picard 1966: 1264-1265, propuso el siglo IV como fecha en la que Cartago comenzó a implantar la organización administrativa de los distritos, apoyándose en las ciudades de su territorio como cabeza de cada uno de ellos. Algo que también corroboraría el hecho de que el segundo tratado entre Roma y Cartago, de 348, incluyera ya a la ciudad de Útica, supeditada a Cartago y situada en su citado territorio conexo.

49 La enumeración de los pueblos y regiones cartagineses situados al oeste de Cartago hace inviable la interpretación vigente del límite de exclusión para la navegación romana descrito en los dos primeros tratados romano-cartagineses y no queda otra opción que asociar el territorio excluido en ellos con Metagonia, al este del cabo Bon. 
ción y tradiciones que permitan afirmar que hubiese alguna forma de administración territorial anterior al siglo III, mientras que, según Picard, este tipo de organización administrativa, referida al territorio conexo a la ciudad de Cartago, se habría implantado durante el siglo IV ${ }^{50}$, tenemos que suponer que la organización de las regiones de Libia tuvo que empezar a ser efectiva a partir de esta última fecha o según el segundo tratado romano-cartaginés, incluso antes, en contra de lo expuesto por González ${ }^{51}$ e incluso corrigiendo a Pérez en lo que éste puntualizó acerca de la provincia de Iberia ${ }^{52}$, pues veremos que la organización administrativa de Iberia debió retomar las realizadas durante la primera mitad del siglo IV, según el segundo tratado romano-cartaginés, con las primeras conquistas que llevó a cabo Amílcar, en 237, para recuperar los dominios cartagineses en la Península Ibérica que parece que se perdieron mientras Cartago estuvo ocupada con la guerra de los mercenarios $(241-237)^{53}$. Dominios que fueron ampliados por Asdrúbal e incluso por las últimas conquistas de Aníbal antes de que cruzara los Pirineos en dirección a Roma, en 218. Así como también tenemos que puntualizar que sí que hay constancia de la imposición de tributos a las ciudades conquistadas por Aníbal ${ }^{54}$, y de la obligación que los pueblos bajo dominio cartaginés tenían de aportar tropas auxiliares al ejército de éste ${ }^{55}$, más allá de la aportada por el propio bronce del templo de Hera Lacinia, claro.

50 Pérez 2003: 17, citando una reprografía de la inédita tesis doctoral de González (Fenicios y Cartagineses en la Península Ibérica) 1983: 441.

51 No sólo en lo que acabamos de ver, que ya corrigió parcialmente Pérez, sino también o al menos matizando lo que éste asintió con aquél acerca de que, antes de las conquistas Bárquidas en la Península Ibérica, Cartago jamás dispuso de ningún territorio que llegara a convertirse en una provincia púnica. Pues es difícil creer que las citadas conquistas Bárquidas fueran las responsables de la organización de las cinco regiones que acabamos de ver que Cartago llegó a tener en Libia, además de la de su propio territorio. Si bien es posible que esta organización se viera influenciada y favorecida gracias a los apoyos económicos que Cartago obtuvo de la Península Ibérica desde que mandó allí a Amílcar, pero con los datos de que disponemos no podemos afirmar ni esto ni lo contrario. Por otra parte, disentimos de Pérez 2003: 17-20, en considerar que, además del propio territorio de Cartago, organizado en distritos, como ya hemos visto, siguiendo a Picard, el resto de los dominios cartagineses en el norte de África constituyeron una difusa región en nada comparable a la otra: Iberia. Coincidiendo con él en que, como veremos, ésta no era una única y monolítica provincia cartaginesa sino que, como él mismo señaló que en 1983 y de otra forma ya apuntara González como hipótesis de trabajo a ser desarrollada pero que nunca lo fue, en Iberia hubo varias regiones (según González serían tres las regiones naturales que habrían podido ser provincias cartaginesas y que después habrían servido de base para la definición de las provincias romanas: Baja y Alta Andalucía, así como Levante, a partir de Cartagena, habiendo dejado al margen de éstas las Baleares y las Pitiusas, López 1995: 76-77 y Pérez 2003: 18), pero disintiendo en que debido a la característica nómada de los pueblos de Libia, toda ella era una única y monolítica provincia.

52 Pérez 2003: 17-18, citando a Whittaker 1978: 169 y ss., también señaló que, según éste, no hay rastro en la documentación acerca de un sistema provincial cartaginés, cuando menos, anterior al siglo III. Añadiendo que, en las fuentes, no hay datos acerca de tributos impuestos a ciudades aliadas africanas, en Cerdeña o en la Península Ibérica. Corrigiendo a éste en lo que respecta a la Península Ibérica, añadiendo que sí existieron pero que lo que no se sabe es la cuantía, el reparto de las cargas, los beneficios fiscales o exenciones, los impuestos indirectos, etc., que sí se mencionan en la epicráteia siciliana, y que lo que sí consta es la probada explotación y beneficio de los filones argentíferos de los distritos mineros de Cartagena y Cástulo, principalmente (apoyándose también en González 1983: 145 y ss.).

53 Polibio escribió: los cartagineses tenían bajo su obediencia a Libia y a muchas partes de Iberia y que además eran señores de todas las islas del mar Sardo y Tirreno, Plb. I 10.5-6, justo antes de que diera comienzo la guerra por la posesión de Sicilia. Así como que, acabada la guerra de los mercenarios: Los cartagineses, en efecto, en cuanto dejaron en orden sus asuntos de Libia y tras haber reclutado tropas, sin dilación despacharon a Amílcar al territorio de Iberia. Éste tomó bajo su mando el ejército y a su hijo, que a la sazón tenía nueve años de edad y, una vez hubo cruzado por las columnas de Hércules, recobró los intereses que Cartago poseía en Iberia, Plb. II 1.5-7.

54 Tras la conquista anibálica de la capital de los olcades, Livio recogió: sacudidas por esta amenaza, las ciudades más pequeñas se someten a su dominio imponiéndoseles un tributo, Liv. XXI 5.4.

55 Véase como ejemplo Liv. XXI 11.13. Relato acerca de la sublevación de carpetanos y oretanos por la dureza de las levas que hacía Aníbal, con motivo del asedio de Sagunto, que citó Pérez 2003: 24, pero sin relacionar este reclutamiento con la dependencia de las ciudades de estos territorios y su supeditación a Cartago. 


\section{LA ORGANIZACIÓN REGIONAL DE CARTAGO EN IBERIA}

Volviendo al texto de Polibio, aún nos falta revisar los detalles con los que comenzó a desgranar la estrategia defensiva de Aníbal y que habíamos pasado por alto al haber entrado directamente a la parte referida a la provincia de Libia sin haber visto la relativa a la de Iberia. A este respecto, Polibio escribió: Los que pasaron a Libia fueron los tersitas, los mastianos, los oretes de Iberia y los olcades: el total de estos pueblos ascendía a mil doscientos jinetes y trece mil ochocientos cincuenta infantes. Asimismo, pasaron (ochocientos setenta) baleares, Plb. III 33.9-11. Lamentablemente, en esta ocasión la reelaboración de Livio no nos sirve de ayuda pues decidió simplificar la información acerca de los pueblos hispanos que pasaron a África, mientras que, por el contrario, aportó detalles acerca de su panoplia: Envió a África trece mil ochocientos cincuenta soldados armados de caetra, ochocientos setenta honderos baleares y mil doscientos jinetes de múltiples nacionalidades entremezcladas, Liv. XXI 21.12-13 y completó también con este tipo de información la que hemos visto que aportó Polibio acerca de la estrategia defensiva de Aníbal $^{56}$, pues el orden que siguió aquél en su reelaboración del texto de éste no fue el mismo.

Aparte de la situación del isleño territorio de los baleares, que por razones obvias no plantea dudas de dónde estuvo esta región, el estudio de las posibles ubicaciones de los territorios de los otros pueblos citados por Polibio en esta ocasión también ha generado una gran controversia entre quienes los han estudiado, habiéndose presentando propuestas muy diversas y poco concluyentes hasta la fecha. Siendo la mayoría o buena parte de ellas hipótesis especulativas que, al no estar contrastadas con una referencia sólida que pudiera facilitar su discriminación, tanto para seguir teniéndolas en cuenta como para ir descartando y cerrando líneas que resultaran inviables por ser incompatibles con ella, siguen estando ahí aunque, para mayor confusión, a veces desaparezcan y reaparezcan según sean las tendencias que primen en cada momento.

En lo que respecta a estos pueblos en concreto, la fuente de la confusión generada acerca de ellos tiene su origen en la propia traducción del texto de Polibio pues, hasta hace una década y debido al gran peso ejercido por la obra de Schulten, en detrimento de la correcta traducción que figura en FHA III ${ }^{57}$, se había venido imponiendo la errónea versión que acabamos de reproducir. Mientras que, últimamente, en lugar de oretes de Iberia ya se ha comenzado a recuperar la alternativa inicial acerca de que, en realidad, se hacía referencia a dos pueblos distintos: los oretes, tradicionalmente identificados con los oretanos, y a los iberos. A pesar de que, como señaló Pérez, cuando se aceptaba la errónea traducción de oretes de Iberia nadie había seguido la propuesta de considerar que los dos primeros pueblos mencionados aparentemente por Polibio también debían de hacer referencia, por similares razones, a uno sólo ${ }^{58}, \mathrm{y}$, sin embargo, había consenso en que lo que quedaba por resolver al respecto era a qué dos pueblos se hacía referencia: tersitas y mastianos. Por lo que creemos que es un gran avance el que se vuelva a identificar a los cinco pueblos a los que se hacía referencia y que ahora no importa

56 Liv. XXI 21.11-12.

57 Pérez 2003: 31-34, revisó la correcta enumeración de los cinco pueblos, dando la razón a la traducción hecha entonces mismo por Trepat y Valentí (Schulten y Bosch 1935: 254), y justificando que, a pesar de ello, triunfara el desafortunado comentario que al respecto hizo entonces Schulten, introduciendo errores gramaticales e históricos, gracias a la autoridad que tenía y que casi ha perdurado hasta nuestros días.

58 Pérez 2003: 33, identificó oretanos e iberos por separado en vez de la lectura tradicional de oretanos de Iberia, mantenida de forma generalizada hasta no hace mucho y, a nuestro juicio, erróneamente como por ejemplo aún hizo Cruz 2002: 170 y 2003: 197-198 y 225, quien también propuso interpretar la orientación de oeste a este de estos “cuatro" pueblos, junto al de los baleares, para ubicarlos siguiendo un corredor entre los ríos Tajo-Guadalquivir que desembocaba en las islas Baleares. 
mucho si poco antes de que así retomara Pérez esta vía también lo hubiera hecho Moret aunque con algunos matices, con los que, además, no coincidimos ${ }^{59}$. Del mismo modo que en la transcripción del segundo tratado entre romanos y cartagineses que hizo Polibio, cabe señalar que al área vedada a la navegación romana que en el primer tratado sólo afectaba, según éste, a la zona situada al Oriente del promontorio Hermoso, esto es a Metagonia y, por tanto, a los emporios cartagineses de esta zona, se añadió la restricción al acceso a los de Mastia y los de Taršiš o, quizá con mayor literalidad, los de los tersitas o tartesios ${ }^{60}$, en el sur de la Península Ibérica y sobre cuya ubicación volveremos más adelante. Con lo que parece que para 348 estos dos territorios del sur de la Península Ibérica debían de estar ya bajo dominio cartaginés. Aunque siempre quedará la sombra de la duda acerca de las asociaciones e interpretaciones mencionadas en este trabajo ya que escaparon a los ojos de Polibio y, por tanto, no las reflejó en su obra ${ }^{61}$.

También tenemos que señalar que la situación de la que partía Pérez para identificar los territorios de cada uno de esos pueblos era muy confusa y que, tras las propuestas que hizo y después de una década, todavía lo sigue siendo y se siguen manteniendo abiertas las grandes cuestiones acerca de quiénes fueron y dónde estuvieron los territorios de los tersitas ${ }^{62}$, mastia-

\footnotetext{
59 Moret 2003: 299-301 consideró la hipótesis de que estos iberos no fueran tales sino una arcaizante traducción al griego del nombre púnico de uno de los pueblos concretos que habitaban en el sur o el sureste de la Península Ibérica. Quizá en la zona montañosa cercana a Cartagena.

60 Espada 2013: 87-88, recogió las diversas opciones para identificar y ubicar ambos territorios, bien como uno mismo o como dos distintos, sin decantarse por ninguna. Sin considerar, como acertadamente hizo Moret 2002: 265-266, que todas las referencias que Polibio extrajo de las placas de bronce de los tratados o de la del templo de Hera Lacinia, de pueblos, ciudades y territorios consistió siempre en listas de nombres individuales yuxtapuestos, con lo que esto implica. Por otra parte, nos parece adecuado considerar que la ciudad de los tartesios debió de estar en la desembocadura del Guadalquivir, como por ejemplo recordó Koch 2003: 2 y 179. Pero no vemos razón alguna para pensar que Mastia fuera la población precursora de Cartagena. Aunque creemos que ésta tuvo que estar cerca del límite nororiental del territorio de Mastia o sea del límite del territorio peninsular que los cartagineses vedaron a los romanos. Un límite que es difícil que estuviera mucho más al norte de Cartagena o del cabo de Palos, y que incluyera la desembocadura del Segura, como propuso Koch 2003: 16, adjudicando erróneamente el territorio de los mastianos al de los tersitas. Sin necesidad de confundir el territorio de Mastia con el Cartago, como identificó Noguera 2013: 139-140 al exponer acertadamente la falta de argumentos para sustentar que ésta fuera la predecesora de nueva Cartago, como se viene considerando.

61 Moret 2002: 262-265 destacó el hecho de que Polibio no identificó las nuevas regiones vedadas a los romanos en la Península Ibérica sino en África. Aunque no tuvo en cuenta el hecho de que en 226 los romanos acordaron con Asdrúbal que el límite que los cartagineses no podían cruzar para hacerles la guerra era el Ebro. Por lo que, al estar Sagunto al sur de este río, lo importante jurídicamente ya no era dónde se encontraba el límite en la península sino si los saguntinos estaban cubiertos por los tratados vigentes, en su calidad de aliados de Roma, tal como podemos ver que razonó Polibio, Plb. III 20-30.

62 Pérez 2003: 34-35, siguió la antigua corriente de identificación de los thersitai con los tartesios del bajo valle del Guadalquivir, explicando a qué se debía la corrupción de su etnónimo en relación con el nombre de Térsites, héroe de la Iliada, como así había hecho ya Moret 2003: 300, y recordando que así se les cita aún en 216, cuando Asdrúbal les declaró la guerra a los tartesios que se habían sublevado al ser incitados a ello por los prefectos de la flota cartaginesa, tras haber sido éstos recriminados por aquél como responsables de la derrota sufrida ante los romanos, en la desembocadura del Ebro, en 217, Liv. XXIII 26.5-11 y 27.1-8. Cruz 2003: 197, también recordó la posible identificación con los tartesios, dejando abierta esta posibilidad. Mientras que Moret 2003: 299, los dio por desconocidos añadiendo que no había motivos para relacionarlos con los tartesios y Álvarez 2010: 404-405, aunque no dudó en ubicar a éstos en el litoral atlántico próximo a Gibraltar, no se pronunció acerca de su posible relación con los tersitas, mantenida por Koch 2003 o por Ferrer 2011-2012: 442-443, quién además realizó una exhaustiva revisión crítica del trabajo de Moret, concluyendo con la identificación de los tersitas o tartesios con los que habitaban al oeste del peñón de Gibraltar, mientras que los mastianos lo harían en al Oriente de éste.
} 
$\operatorname{nos}^{63}$, oretes $^{64}$, iberos ${ }^{65}$ e incluso los esquivos olcades ${ }^{66}$. Esto se debe, seguramente, a que las hipótesis de la bien encaminada aproximación de Pérez no dejaron de ser consideradas como otras más que añadir a la larga lista existente y el hecho de que estuvieran sustentadas por el análisis de parte del texto del bronce del templo de Hera Lacinia creemos que no contribuyó a que fueran consideradas de otra forma por la historiografía reciente ${ }^{67}$. De ahí que no hayan supuesto un antes y un después en la investigación de estos temas. Seguramente porque, como veremos, aunque Pérez extrajo información interesante y no muy desencaminada en lo que respecta a la organización administrativa de la provincia cartaginesa de Iberia ${ }^{68}$, no profundizó en saber y,

63 Pérez 2003: 35-36, citando a Hecateo de Mileto y remontándose con ello al siglo VI o V, asoció a los mastianos como el pueblo cuya capital era Mastia y cuyo territorio se encontraba hacia las Columnas de Hércules. Añadiendo que, citando a Teopompo, ésta era una región alejada del territorio de los tartesios, como también expusieran García 1990: 57 y Moret 2003: 301, a quien éste no citó. Así como que a partir de los comentarios de Schulten en las FHA fue como se delimitó el territorio de los mastianos entre el Estrecho de Gibraltar y Cartagena. Recapitulando con una referencia al estado del conocimiento sobre la situación de los mastianos a los que se les situaba cerca del citado estrecho, extendiéndose algunas de sus ciudades por la Costa del Sol. Del mismo modo que Moret 2003: 300, citando a García 1990: 60 y 64, que ubicó la ciudad de Mastia en la bahía de Algeciras e identificó a los mastianos con los bastetanos, como también hicieron Ferrer y de la Bandera 1997, o Ferrer 2010-2011: 442-443, García 2012: 399 y Ferrer y Pliego 2013: 115 y 118, situando a los tartesios y mastianos a ambos lados del Peñón de Gibraltar. A pesar de que Moret 2002 ubicara erróneamente Mastia en el norte de África, siguiendo a Polibio, o de que Maras 2007: 410-418, la llevara al sur de Italia.

64 Pérez 2003: 37, también identificó a los oretes con los orisses que acabaron figurando en las fuentes como oretanos, ocupando la actual provincia de Jaén y la parte sudeste de la de Ciudad Real. Añadiendo que había unanimidad acerca de esta identificación, al igual que hizo Moret 2003: 297 y 300-301, que también lo consideró así, remontándose a Tovar 1989: 28-30.

65 Pérez 2003: 37-38, descartó la posibilidad de identificar a estos iberos con un pueblo que supuestamente habitó un territorio del sudoeste peninsular y que Schulten había delimitado entre los ríos Tinto y Guadiana. Identificándolos con los habitantes del Levante hispánico, que emplearon la escritura ibera y que, posteriormente y citando a Plinio, figuran deslindados en las regiones romanas de Deitania, Contestania, Edetania y parte de los ilergavones, pero sin citar a Domínguez 1983: 209 y 212-219 o Cruz 2003: 211, que ya habían expuesto todo esto sobre los iberos e Iberia. Región que Cruz 2003: 200 y ss., también llegó a plantearse como la inicialmente correspondiente a los iberos antes de que esta denominación pasara a referirse a los habitantes de la costa mediterránea, desde las Columnas de Hércules hasta los Pirineos. Por otra parte, también señaló Pérez que esta era una de las pocas ocasiones en las que los iberos figuran en las fuentes antiguas como tales o sea como una entidad administrativa única, sin deslindar los pueblos que formaban parte de ella. Considerando que, sin embargo, Polibio extendió la referencia como iberos a los de las actuales regiones de Aragón y Cataluña, especialmente al narrar sucesos posteriores al desembarco romano de 218 , algo en lo que no estamos completamente de acuerdo. Aunque, como Pérez y, en cierto modo, como Moret 2003: 280, 289 y 301, que acertó a distinguir la referencia a los iberos de Aníbal del resto de referencias que Polibio hizo a los iberos, pensamos que el territorio de éstos se encontraba en el corredor de Levante, al norte de Cartagena y al sur del Ebro. Territorio éste en el que Polibio era conocedor de la existencia de diversos pueblos iberos, como por ejemplo, el de los edetanos, Plb. X 34.2, y sobre lo que volveremos un poco más adelante. Aunque no compartimos la opinión de Moret 2003: 288-292, acerca de que Polibio consideró a los ilergetes entre los iberos pues no encontramos base para tal afirmación.

66 Pérez 2003: 38, expuso que últimamente se ubica a los olcades en la actual provincia de Cuenca a pesar del extenso debate que la posible etnicidad y situación territorial ha registrado en la bibliografía, como recogió Gozalbes 2000: 73-120 o Burillo 2008: 183 y 188-192, y, de forma similar, también Moret 2003: 301. Si bien creemos que la propuesta de éste último es la que más se parece a la que proponemos nosotros para la ubicación de los olcades.

67 Aunque es posible que la obra de Salinas pudiera considerarse tendenciosa por no citar ningún trabajo de Pérez, no nos cabe duda de que en una revisión actualizada como ésta, acerca de los pueblos prerromanos de la Península Ibérica, no habría tenido más remedio que citar sus propuestas de haber sido éstas contrastadas y aceptadas de forma generalizada. Algo similar se puede decir del reflejo del estado de la cuestión presentado por Burillo acerca de los celtíberos, quien también trata acerca de estos temas pues indirectamente tienen que ver con la insostenible tesis de Capalvo 1996 acerca de Celtiberia y, aunque citó a Pérez, para nada hizo mención de este trabajo en concreto, Salinas 2006 y Burillo 2008.

68 Pérez 2003: 39-41, creyó que la referencia a los cinco pueblos enumerados por Polibio se correspondían con la división administrativa que los cartagineses habían realizado en su provincia de Iberia hasta 219, sujeta a la soberanía de Cartago o a la de los Bárquidas, más exactamente al nivel cronológico del mandato de Aníbal sobre la "provincia" pues, para Pérez, Cartago tuvo dos provincias o dominios: Libia e Iberia, cuyas distribuciones administrativas internas no eran comparables, siendo mucho más compleja y desarrollada la de esta última. También señaló que la distribución de los cinco distritos cartagineses de Iberia no tenía por qué coincidir con las distribuciones de los territorios de los pueblos mencionados en sus denominaciones, ya que tal identificación sólo reflejaba la selección hecha por los cartagineses a la hora de 
por tanto, en explicar en qué consistió realmente la estrategia defensiva planeada por Aníbal para las provincias de Libia e Iberia y, al no comprender el texto del que partía y las implicaciones que éste tenía con respecto a la organización administrativa de Cartago en las provincias de Libia y de Iberia, ni su vinculación con los primeros tratados entre Cartago y Roma, acabó llegando a conclusiones que no se correspondían con la información transmitida en él.

No obstante, tenemos que seguir destacando la importancia que creemos que tiene el trabajo de Pérez, pues fue muy acertada su aproximación de considerar el estudio de este episodio de la obra de Polibio como si a través de él se estuviera realizando el análisis epigráfico de la propia placa de bronce que éste describión ${ }^{69}$. Esto es, el enfoque de aproximarse a este estudio como si se tratara del análisis de un documento epigráfico desaparecido pero del que quedara una fidedigna y detallada descripción de una parte de él que afortunadamente es autocontenida. Con esta interesante perspectiva creemos que, junto con Moret, abrió un cauce nuevo para abordar y empezar a responder las cuestiones que decíamos que siguen estando abiertas ya que, si se logra concluir con éxito su hermenéutica, a partir de ese momento la información aportada por el bronce del templo de Hera Lacinia se podrá considerar como un fósil director con el que contrastar las hipótesis previas y sobre el que apoyar las nuevas. Especialmente si, como veremos, se pone en relación con el resultado de las autopsias a los bronces de los primeros tratados entre romanos y cartagineses que realizó Polibio. A pesar de que éste no fuera consciente de dicha relación por no haber comprendido el significado de los pueblos citados en el bronce del templo de Hera Lacinia.

En nuestro caso, creemos que la clave que nos está permitiendo abordar adecuadamente la interpretación del bronce del templo de Hera Lacinia ha sido la de tener en cuenta dicha relación y poder determinar cuál era la región de Metagonia y considerar que tanto ésta como los territorios de los otros cuatro pueblos de Libia que entonces estaban bajo dominio de Cartago no eran otra cosa que las cinco regiones cartaginesas de Libia, además de la que constituía el territorio directamente dependiente de Cartago. Una vez visto esto y comprendida la importancia estratégica que tenía la defensa de Metagonia frente a un potencial desembarco romano procedente de la cercana Sicilia, desde los inicios de la república de Roma y, en particular, ante el comienzo de la Segunda Guerra Púnica, se comprende también la estrategia de Aníbal para defender el territorio de Cartago en Libia. Estrategia en la que sobresale la defensa de la propia Cartago y de su primera línea de protección metagonita, así como la menos importante defensa de las otras cuatro regiones occidentales del norte de África, seguramente porque también era menos probable que el potencial ataque romano, de producirse, fuera a darse por allí. Desta-

identificar cada una de estas regiones administrativas por el nombre del pueblo que más destacaba en cada una de ellas, aunque no coincidiera con el territorio de éste ni eso quisiera decir que en ellas no hubiera más de un pueblo y, mucho menos, que se hablara una única lengua, etc. También creyó que los distritos correspondientes a los tartesios, mastianos e iberos coincidían con los propuestos por González como antecedentes de las futuras provincias romanas: Baja y Alta Andalucía y Levante, respectivamente. Pagi que, según Pérez, serían complementados por los de los oretanos y olcades con los correspondientes sectores de Sierra Morena oriental y los aledaños norteños de la submeseta meridional y, en fin, a la zona de La Mancha oriental o donde quiera que se situasen los olcades. Añadiendo que tanto este último pagus como el de los iberos, fueron creados por Aníbal, propuesta ésta en la que estamos también de acuerdo con Pérez. Aunque no así con su hipótesis de que sería muy probable que el orden de mención de los cinco pueblos fuera indicativo de una mayor o menor permanencia de cada uno de ellos bajo dominio cartaginés pues, aunque seguramente es así, dicho orden veremos que no sólo implicaba esto. Así como también disentimos de su apreciación acerca de que los carpetanos y otros pueblos que estaban al sur del Ebro y que, según Polibio y Livio (Plb. III 14.9-10 y Liv. XXI 5.17). fueron completamente sometidos a Cartago en época de Aníbal, no llegaron realmente a estarlo o, mejor dicho, no tanto como para formar parte de los supuestos pagi ibéricos de Cartago. Ni tampoco coincidimos con las apreciaciones o consideraciones que a continuación hizo Pérez acerca del resto de pueblos hispanos no incluidos en las cinco supuestas demarcaciones administrativas, al menos no en lo que respecta a su relación con éstas.

69 Algo que también había señalado Moret 2003: 299. 
cando el hecho de que al estar todas las regiones y el territorio propio de la misma Cartago situadas en el litoral mediterráneo, no nos cabe duda de que la enumeración de sus regiones fue exhaustiva, cosa que veremos que no ocurre en el caso de la defensa de la provincia de Iberia. Pues para defender los dominios cartagineses en la Península Ibérica es cierto que igualmente Aníbal debió pensar, como veremos que así hizo, en asegurar las regiones del litoral, desde el extremo en el que confluye con las costas del océano Atlántico hasta la margen derecha del Ebro, ya que ese era su límite en el invierno de 219-218 o, mejor dicho, desde 226.

Nuevamente, el orden en el que están descritas las regiones cartaginesas de la provincia de Iberia involucradas en su defensa no es casual y, de oeste a este, describe las que cubren todo el litoral costero así como las que controlaban los accesos o principales vías de comunicación con el interior de la Península Ibérica, a través de la meseta sur, tanto entre ésta con el valle del Guadalquivir y las regiones del sudoeste peninsular, como, tras cruzar el río Tajo, entre dicha meseta y la norte o el valle del Ebro.

El territorio de los tersitas creemos que estuvo en el bajo valle del Guadalquivir (Betis/ Tersis) y que hacía referencia a la región que controlaba la costa allende las Columnas de Hércules o, si se prefiere, más allá del actual peñón de Gibraltar pero sin incluir las estribaciones occidentales del sistema Bético ya que creemos que éste y su correspondiente franja costera, atlántica y mediterránea, correspondían al territorio de los mastianos ${ }^{70}$. A partir del territorio de los mastianos se citan las dos regiones que eran limítrofes con éste, la de los oretanos, que controlaba el acceso desde el límite septentrional del territorio de los mastianos en la costa mediterránea ${ }^{71}$, al alto valle del Guadalquivir y a las regiones del sudoeste y oeste peninsular; y la región de los iberos, que controlaba el resto del litoral mediterráneo hasta la orilla derecha del río Ebro. Completando la enumeración de las regiones involucradas preventivamente ante un posible contraataque romano, la interior de los olcades, que controlaba el paso desde el levante mediterráneo de Iberia al resto de los territorios cartagineses del interior peninsular a través de la meseta meridional.

70 En los citados trabajos de Ferrer 2011-2012 y Ferrer y Pliego 2013, se propuso al peñón de Gibraltar como separador entre tersitas y mastianos.

71 Estrabón, al describir los pueblos situados al este de la región que hay entre el promontorio Sagrado (cabo de San Vicente) y el Tajo, escribió: Los primeros que se encuentran situados hacia el interior de las mencionadas regiones son los oretanos; son los más meridionales y los que se extienden hasta el litoral de la parte de más acá de las Columnas, después de éstos, hacia el norte, los carpetanos, luego los vetones y los vacceos, a través de cuyos territorios fluye el Duero, Str. III 3.2 y al describir la costa mediterránea: Desde Calpe, la montaña de las Columnas, hasta Cartago Nova se dice que hay dos mil doscientos estadios (esta costa está habitada por bastetanos, a los que también se denomina bástulos, y en parte también por oretanos), Str. III 4.1, insistiendo en que: A continuación de los celtíberos hacia el sur [este] se hallan los sedetanos, que habitan la cadena montañosa de la Orospeda y el territorio de los alrededores del Sucro hasta Cartago Nova, y los bastetanos y los oretanos casi hasta Malaca, Str. III 4.14, insistiendo en la idea de que la parte septentrional del Sistema Bético pertenecía a los oretanos, escribiendo: Comenzando en detalle, a partir de Calpe se halla la cadena montañosa de la Bastetania y de los oretanos, con un bosque frondoso y grandes árboles, que delimita el litoral de las tierras del interior; en muchos lugares de alli existen minas de oro y de otros metales, Str. III 4.2. Por lo que no hay duda de la existencia de una parte costera de Oretania. Así como de que, entre Cádiz y el peñón de Gibraltar, todavía era territorio de los bastetanos: La Turdetania que atraviesa el río Betis se extiende hacia el interior del litoral de este lado del Anas. El río Anas la delimita hacia el oeste y el norte, y una parte de los carpetanos y los oretanos hacia el este, hacia el sur aquellos de los bastetanos que habitan el estrecho litoral situado entre Calpe y Gades, y el mar que viene a continuación hasta el Anas (los bastetanos que mencionamos también pueden incluirse dentro de la Turdetania y los que habitan más allá del Anas y muchos otros de los pueblos limitrofes.), Str. III 2.1. 


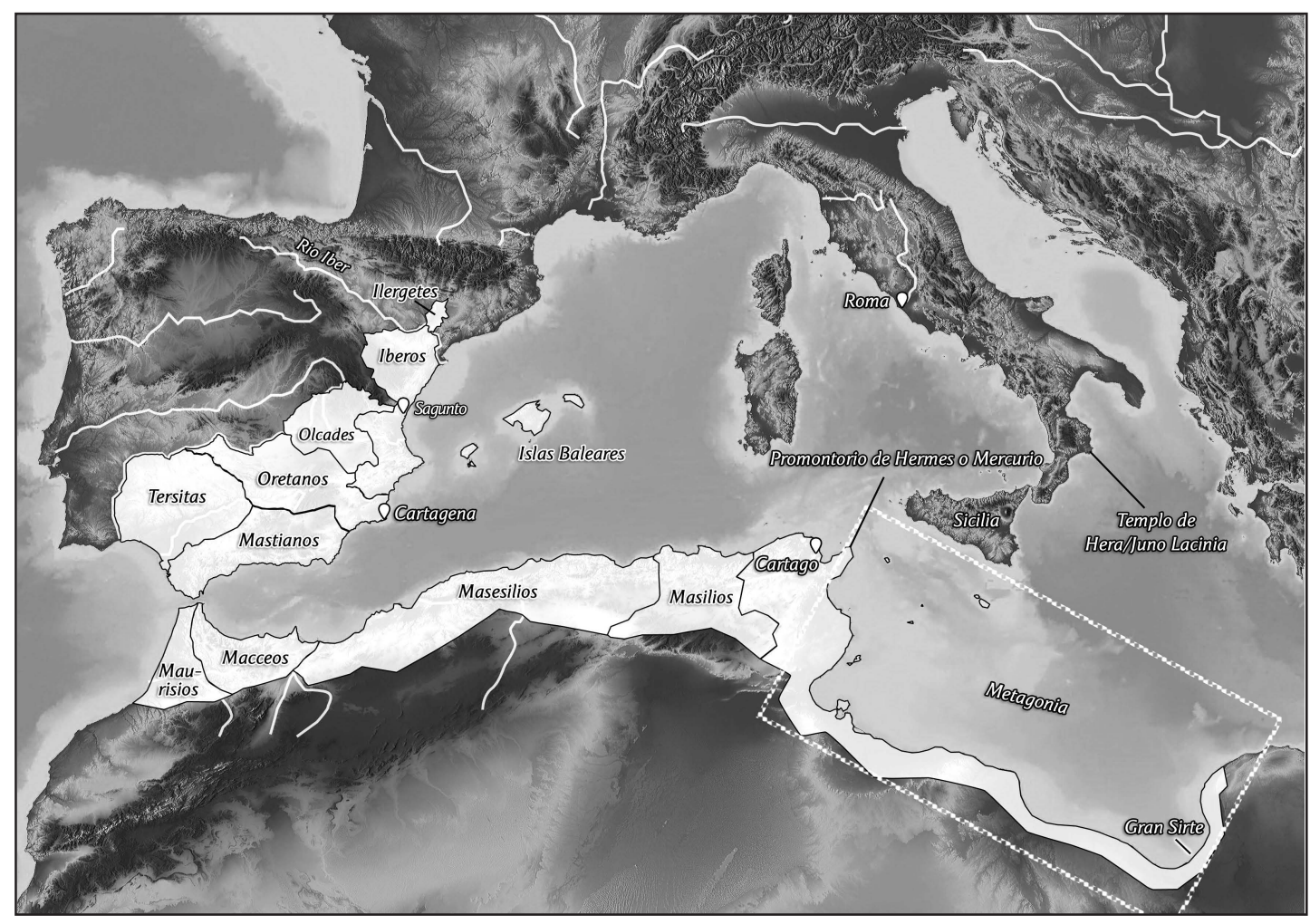

Figura 3. Distribución de las regiones cartaginesas afectadas, en Libia y en Iberia, por la estrategia defensiva de Aníbal, en 219-218.

\section{LAS OTRAS REGIONES DE LA PROVINCIA DE IBERIA, COMO CELTIBERIA O LU- SITANIA}

Entre los autores contemporáneos a los que hemos visto que aludió Estrabón, y que consideraban sinónimos Iberia e Hispania para referirse con cualquiera de estos dos términos a la Península Ibérica, creemos que también se encontraba Polibio o que si no fue así, podía haberlo sido ya que, en general, éste también identificó Iberia con Hispania o sea con la Península Ibérica ${ }^{72}$. Sólo en dos ocasiones ${ }^{73}$ usó Iberia de forma diferente y con carácter restrictivo o sea refiriéndose a la región cartaginesa de Iberia: la primera implícitamente, cuando Polibio

72 Evolución semántica de Iberia e iberos que nada tuvo que ver con el progresivo conocimiento de la Península Ibérica desde la costa mediterránea, pasando por el interior hasta ir llegando a las costas atlánticas, como se ha venido creyendo hasta ahora, Domínguez 1983: 212-214 y 221-222, y en contra también de lo expuesto por Moret 2003: 280 y 286-288 acerca del uso de estos términos que hizo Polibio, por ejemplo.

73 Creemos que no se debe confundir, como se ha venido haciendo, como por ejemplo: Domínguez 1983: 203, Ciprés 1999: 130 y 141, Pérez 2000: 22, Cruz 2002: 167 y 2003: 196, Moret 2003: 279-281, 284 y 288-293, Ciprés 2006: 181182 y Marcotte 2006, el hecho de que Polibio dijera que la parte de Europa bañada por el Gran Mar u océano Atlántico no tuviera una denominación común y que estuviera habitada por muchos y muy diversos pueblos bárbaros que sólo entonces empezaban a conocerse, Plb. III 37.10-11, con el de que no se conociera entonces la región correspondiente al oeste y noroeste de la Península Ibérica, de la que Polibio debía tener buena información pues no se refirió a ésta sino a aquella. De modo que la suposición de que en esta ocasión Polibio identificara Iberia con la franja costera que iba desde los Pirineos hasta el océano es errónea. En contra de lo expuesto por Domínguez 1983: 203 y 215 al interpretarlo así y decir que precisamente ese territorio es el que se venía entendiendo ahora como Iberia. 
se refirió a los iberos citados por Aníbal o sea a los habitantes de la región cartaginesa de Iberia, tal como hemos visto ${ }^{74}$, y la segunda al referirse a la situación de Sagunto, diciendo: Esta ciudad está situada, por el lado que cae al mar, al pie de una cadena montañosa que une los extremos de Iberia y Celtiberia y distante del mar como unos siete estadios, Plb. III 17.1 ${ }^{75}$, haciendo referencia a que Sagunto se encontraba en la antigua región de Iberia, al pie de la cadena montañosa que en ella tenía uno de sus extremos ${ }^{76}$, mientras que el otro lo tenía en la región de Celtiberia, según la práctica de delimitar un territorio por medio de la referencia a sus extremos ${ }^{77}$, como también hizo al referirse a Lacetania sin nombrar a ésta ${ }^{78}$. Pues, en esta ocasión, creemos que Polibio también se refirió a Iberia y además a Celtiberia — siendo ésta la referencia literaria más antigua a esta región que se conoce - como a las correspondientes regiones cartaginesas cuya ordenación debió de conocer de primera mano. No sólo por las fuentes que manejó sino también porque aún quedarían reminiscencias de ellas entre los habitantes con los que departió en su viaje a Iberia/Hispania de $151^{79}$, y cuya etnogeografía debió describir después. En el desaparecido libro XXXIV ${ }^{80}$, con la posible finalidad de que, a modo de corolario, sirviera de puente entre la organización cartaginesa obsoleta, que había venido manejando y citando en sus primeros libros para describir los episodios relacionados con la Segunda Guerra Púnica, y la reorganización de los pueblos indígenas y de sus territorios fruto de su paulatina incorporación al dominio romano. De acuerdo con la evolución del término Iberia hasta convertirse éste en un sinónimo de Hispania y que el territorio de esta provincia evolucionara también para dar lugar, de hecho, a las provincias de Hispania citerior y ulterior, tomando al Ebro como frontera inicial entre ambas, en 205, hasta que ésta fue definida formalmente o redefinida en 197, 132 y 27 (incluyendo el período de 171-167 en que ambas provincias, aún permaneciendo como en 197, constituyeron una única provincia romana).

74 Dato que desmonta la hipótesis de partida de Domínguez 1983: 209, e invalida buena parte de las conclusiones de su trabajo, así como el de tantos otros antes y después de él.

75 Así lo reflejó Livio, a pesar de que Polibio omitió los detalles aportados por éste acerca de la segunda parte de la campaña de Gneo Cornelio Escipión en 217, cuando relató que, tras la victoria naval que obtuvo en la desembocadura del Ebro: Confiando pues lo suficiente también en las tropas de tierra, Escipión avanzó hasta el desfiladero castulonense, Liv. XXI 20.12 mientras que Polibio escribió que Pues los romanos antes [de que llegara Publio, hermano menor de Gneo] jamás se habían atrevido a cruzar el río Ebro, Plb. III 97.5. Creemos que Polibio, en esta ocasión, además de que en general no aportó muchos de los detalles acerca de los pueblos hispanos que después sí recogió Livio, y eso que creemos que debía conocerlos y haber manejado críticamente, no sólo las fuentes antiguas que empleó éste, sino también haber sido protagonista de algunos de los acontecimientos narrados, o de haber conocido de primera mano los lugares y a algunos de los que habían participado en estas campañas desde el principio de las mismas, como él mismo señaló: Plb. III 4.13, 9.1-5, 48.12 y 59, tuvo especial interés en destacar el papel desempeñado por Publio Cornelio Escipión en Iberia, dada su conocida relación con los descendientes de éste y quizá con el contexto en el que comenzó a escribir sus Historias, en Roma.

76 Livio registró que los olcades eran vecinos de los saguntinos: Como el atacarlos iba a provocar con toda seguridad una reacción armada por parte de los romanos, llevó primero a su ejército al territorio de los olcades —pueblo éste situado en el territorio de los cartagineses más que bajo su dominio, al otro lado del Ebro- para que pudiese dar la impresión, no de que había atacado a los saguntinos, sino de que se había visto arrastrado a esta guerra por la concatenación de los hechos, una vez dominados y anexionados los pueblos circundantes, Liv. XXI 5.3-4. Por lo que el extremo oriental de los olcades era limítrofe al occidental de los saguntinos.

77 Plb. III 17.2. Interpretación que ya propuso Domínguez 1983: 218, identificando Iberia y Celtiberia como las regiones en las que se encontraban los extremos de la cordillera de la Idubeda o actual sistema Ibérico.

78 Polibio citó los pueblos de los extremos de Lacetania, Plb. III 35.2, sin mencionar esta región, a diferencia de Livio, Liv. XXI 23.2, gracias a cuya descripción etnogeográfica, podemos compararla con la de Polibio y así comprender cuáles fueron dichos pueblos.

79 Díaz 1972: 37-38.

80 Si bien hemos visto que su tercer libro fue escrito antes del cambio del año consular, por lo que la primera cita a Celtiberia la tuvo que escribir Polibio antes de 154 y de su viaje a la Península Ibérica, en 151. En contra de lo expuesto por Pérez 2000: 22-23, por ejemplo, en lo que respecta a cuándo debió de escribir Polibio sus obras. 
No podemos aventurar los nombres ni la situación del resto de regiones cartaginesas de la provincia de Iberia con excepción de la citada Celtiberia así como de Lusitania ${ }^{81}$ y las de los territorios de otros pueblos que igualmente pudieron corresponder también a otras tantas regiones, como pudo ser el caso del territorio de los vacceos ${ }^{82}$, el de los carpetanos ${ }^{83}$, y el de los vetones así como también el de los túrdulos y turdetanos aunque éstos, como posteriormente también ocurrió con algunos lusitanos y celtíberos, sufrieron deportaciones por parte de los romanos que conllevaron su reubicación parcial o total en otros lugares. Pues aunque parece que Polibio también los mencionó independientemente, creemos que con sólo esa información y debido a los pocos fragmentos de su libro XXXIV que se han conservado, no es posible saber si los territorios de dichos pueblos correspondieron a otras tantas regiones cartaginesas o si su organización como tales regiones ya correspondía a alguna de las posteriores reorganizaciones romanas $^{84}$. Es posible, que contrastando la información de otras fuentes con la propuesta que aquí hacemos, revisando lo ocurrido diacrónicamente a lo largo del siglo II con respecto a este punto de partida, de finales del siglo III, se pueda llegar a perfilar mucho mejor la distribución administrativa de las regiones cartaginesas que llegaron a quedar bajo dominio de Aníbal, así como conocer mejor la etnogeografía prerromana de toda la Península Ibérica.

También queremos señalar la posibilidad de que la región cartaginesa de Iberia, en la que luego consta que hubo varios pueblos con su posible diversidad cultural, como por ejemplo el de los edetanos ${ }^{85}$, debiera su nombre al de su posible capital regional, que podría ser la que según Livio era la ciudad más opulenta entonces de aquella comarca, ciudad llamada Hibera ${ }^{86}$ por el río que tenía cerca ${ }^{87}$, Liv. XXIII $28.10^{88}$. Del mismo modo que parece que la ciudad de Mastia pudo dar soporte administrativo a la región de los mastianos y a diferencia de la de los olcades, cuya capital ${ }^{89}$ no parece que contribuyera con su nombre al de su correspondiente región. De lo que también deducimos que no hay por qué dar por sentado que en todos los casos debió de existir una correlación biunívoca entre los territorios de los pueblos que habitaban y

81 Por autores posteriores que citaron la obra de Polibio, en este caso de Ateneo VII, hay constancia de que una de las regiones y, seguramente, regiones cartaginesas de Iberia era Lusitania, Plb. XXXIV 8, citando a sus habitantes como lusitanos, Plb. XXXV 2.2.

82 Basándonos en la cita que hizo Estrabón a los pueblos y a las ciudades tanto de los vacceos como de los celtíberos, Plb. XXXIV 9.13, según Str. III 4.13, quién añadió a las ciudades celtíberas que enumeró las de Segisama e Intercatia ya que así debían figurar en la obra de Polibio y Ateneo I 16.

83 Polibio distinguió a los vacceos de sus vecinos celtíberos y de los que habían sido vecinos de ambos, los carpetanos. Siendo estos dos últimos vecinos, a su vez, de los olcades, Plb. III 5.1 y 14. Asimismo, citó entre los pueblos celtíberos a los belos, titos y arévacos, Plb. XXXV 2.3-4, 11 y 13.

84 La cita de Estrabón, acerca de que Polibio, Str. III 2.11, situó el nacimiento de los ríos Guadiana y Guadalquivir en Celtiberia, Plb. XXXIV 9.12, así como la cita en la que Polibio distinguió a varios pueblos celtíberos en 154, hacen referencia a momentos históricos posteriores en los que la situación era diferente que a finales del siglo III. Así, en Olcoz y Medrano 2011, vimos que a principios del siglo II los celtíberos se expandieron por sus territorios vecinos, tal como señalara el propio Estrabón: los celtíberos, como habian acrecentado su poder, hicieron que los territorios vecinos recibieran el mismo nombre que ellos, Str. III 2.11, lo que explicaría que por el sur llegaran a dominar aquellos en los que se encontraban las fuentes de los citados ríos, y que, una vez conquistada Celtiberia por los romanos, éstos dividieron su territorio entre los de varios de sus componentes y pactaron directamente con sus ciudades en lugar de hacerlo con los representantes de ellos, como habían hecho en 217.

85 Plb. X 34.2.

86 Hibera se viene situando en Tortosa pero en la margen derecha del Ebro, Domínguez 1983: 219, Pérez 1987: 173, Pérez 2008: 58 y Noguera 2008: 39. A diferencia de Dertosa que también estaba en Tortosa pero en la margen izquierda del Ebro, como puntualizó Arasa 2001: 57.

87 De Hoz 2011: 26, no dejó dudas a que el río Hiberus dio nombre a los iberos.

88 Según Estrabón, la ciudad de Tarteso tomó su nombre del río en cuya desembocadura se situaba, aunque luego éste pasó a ser denominado Betis, situando en el territorio de Tarteso a los turdetanos y túrdulos, Str. III 2.11. Koch 2003: 179, relacionó acertadamente el nombre antiguo del Betis, citado como Certis por Livio, Liv. XXVIII 22.1, con Taršiš.

89 Altea según Plb III 13.6 o Cartala según Liv. XXI 5.4. 
dominaban una región cartaginesa y el territorio de ésta ${ }^{90}$. Así como que alguna de estas regiones, por tanto, pudo corresponder a una demarcación administrativa, con su correspondiente capital regional, cuyo sentido era pleno para los cartagineses pero que quizá no lo era tanto para todos los pueblos que habitaban en ella. Los cuales creemos que, de haberse dado este caso, seguirían manteniendo su capital indígena dependiente ya de la regional, si es que no siempre eran o acabaron siendo la misma ciudad.

Aunque también creemos que estas regiones tampoco debieron de ser completamente arbitrarias o artificiales ya que el breve período del dominio cartaginés sobre algunas de ellas tampoco debió de ser suficiente como para consolidar demarcaciones creadas artificialmente por los cartagineses sin que éstas respetaran los límites y la organización de los territorios de los pueblos que formaban parte de ellas, como tal vez pudo ser el caso de la de Iberia, por ejemplo. Así como que si hubo alguna más de este tipo tampoco su estabilidad y consolidación sería equiparable a las constituidas a partir de territorios cuya organización previa coincidiera con la correspondiente región cartaginesa. Por lo que si hubo alguna que no fuera de este último tipo, creemos que eso también debió contribuir a que después los romanos no mantuvieran la distribución regional cartaginesa tal como la encontraron. Especialmente a partir de 197, ya que desde entonces ni siquiera respetaron algunos de los ancestrales límites territoriales de algunos de los pueblos profundamente asentados y organizados en ellos. Al fin y al cabo, algunas regiones de este tipo, si las hubo, estuvieron vigentes sólo unos pocos años o, como máximo y para las que más tiempo se mantuvieron bajo el yugo cartaginés, poco más de tres lustros en algunos casos. Por lo que también sería de esperar que su rastro se hubiera perdido como consecuencia de la redistribución de algunos de los territorios de los pueblos que las formaban, de acuerdo a su conveniencia. En particular, para aquellos que en 197 pasaron a formar parte de las recién delimitadas formalmente provincias romanas de Hispania citerior y ulterior. Algo que también ocurrió más tarde con otras regiones, concretamente con alguna de las situadas al norte del Ebro, como fue el caso de Lacetania, en cuya formación no parece que hubieran intervenido los cartagineses y cuyo territorio cambió, en 206, debido a la influencia de Roma.

Del mismo modo que en otros casos, como el de la región de Celtiberia, en la que tenemos un particular interés, por ejemplo, en cuya gestión del territorio los romanos no intervinieron hasta que la dividieron en 167, dando también lugar o haciendo aflorar la organización de algunos de los pueblos o distritos que formaban o a partir de entonces pasaron a forma parte de su organización interna. Siempre alrededor de sus correspondientes capitales o, conforme fue avanzando su romanización, ciudades estado, que eran las entidades con las que se articulaba o acabó articulándose el territorio de todas las poblaciones dependientes de ésta ${ }^{91}$.

Por último, creemos que cabe recordar que el inicio de la recuperación de la provincia cartaginesa de Iberia fue mérito de Amílcar y que quien la engrandeció, llevando su frontera septentrional hasta el mismo río Ebro, y quien fundó una nueva Cartago desde la que rivalizó y cuestionó la hegemonía de la vieja Cartago, obteniendo incluso el reconocimiento internacional de Roma, fue Asdrúbal. Así como que frente al gobierno casi independiente y, en cualquier

90 Estrabón recogió que la región de Lusitania estaba compuesta por unos 30 pueblos en los que había ciudades que los romanos convirtieron en aldeas así como también crearon otras nuevas ciudades: Así pues son unas treinta las tribus que se distribuyen el territorio que existe entre el Tajo y los ártabos. Pero aunque el territorio es próspero por los frutos, el ganado y por la gran cantidad de oro, plata y metales parecidos, sin embargo la mayor parte de sus habitantes han abandonado el sustento procedente de la tierra y pasaban su tiempo en medio de pillajes y en continua guerra entre si y contra los vecinos (para lo que cruzaron el Tajo), hasta que los romanos les hicieron cesar en estas actividades, les bajaron los humos y convirtieron en aldeas la mayor parte de sus ciudades, en cambio algunas de ellas las fundaron en mejores condiciones con el añadido de colonos, Str. III 5.

91 Olcoz y Medrano 2011: 114. 
caso, completamente autónomo de Asdrúbal, el de Aníbal supuso el retorno de esta provincia al gobierno jerárquico de la vieja Cartago. Del mismo modo que también fue de éste el mérito de lograr el sometimiento de todos los pueblos situados al sur del Ebro y el de que todas sus regiones contribuyeran con tropas para llevar a cabo la campaña contra Roma, así como para desplegar su innovadora estrategia defensiva en ambas provincias cartaginesas. Añadiendo por último, que también le corresponde a Aníbal el mérito de ser quien, con el apoyo del rey ilergete, Indíbil, creó en el verano de 218 la tercera y efímera provincia cartaginesa al norte del Ebro o la nueva región en que se convirtió esta comarca, llevando los límites de Iberia hasta los Pirineos. Claro antecedente de la provincia romana que, en otoño de ese mismo año, comenzó su andadura como Hispania o la que desde 226 fue conocida con este nombre, situada ésta entre el Ebro y los Pirineos, manteniendo dicho límite septentrional, y que, en 205, fue transformada por el Senado de Roma en la primera edición de la provincias de Hispania citerior y ulterior, basándose en la alianza romana con cada uno de los pueblos que habitaban en sus respectivas regiones. Hasta que los límites de ambas provincias fueron formalmente definidos al margen de ellos en 197, por primera vez y con la consiguiente sublevación de los pueblos afectados, ampliados en 132, para incluir Celtiberia en la Hispania citerior entre otros de los cambios realizados entonces, y acabar en 27 distribuyendo toda la Península Ibérica entre las tres provincias romanas: Tarraconense, Lusitania y Bética, que también tuvieron su posterior evolución.

\section{UNA MANIOBRA DEFENSIVA ASEGURADA POR MEDIO DE REHENES Y REFUER- ZOS}

Poco más hay que añadir acerca de cómo Aníbal aseguró la maniobra defensiva con la que llevó a término el tercer punto de su estrategia, pues hemos visto que él mismo dejó escrito en qué consistió y cómo se ejecutó.

Cabe reseñar que la información cuantitativa acerca de la cantidad y composición de las tropas que pasaron entonces de la provincia cartaginesa de Iberia a la de Libia (1.200 jinetes, 13.850 infantes y 870 honderos $\left.^{92}\right)$ y la de las que hicieron el traslado contrario (2.550 jinetes y 12.650 infantes así como 21 elefantes), fueron muy parecidas, salvando las características específicas de los baleares y de los elefantes, que no tenían contrapartida en sus correspondientes lugares de destino. De lo que deducimos que un contingente básicamente contrarrestó la deficiencia generada por el traslado del otro. De modo que esta estrategia no introdujo ningún desequilibro en las fuerzas que había destinadas a la defensa de cada provincia. Tampoco llama la atención el número de cada uno de estos contingentes, si se compara con la cantidad de tropas que movilizó Aníbal cuando poco después emprendió su marcha hacia Roma o si se tiene en cuenta el gran número de guerreros que habitualmente suelen integrar los ejércitos indígenas, tanto los que consta que se enfrentaron con éste durante los dos años previos a su campaña, como los que después se movilizaron contra romanos y cartagineses, etc. ${ }^{93}$. Por lo que resulta notorio que, en esta estrategia anibálica, era más importante su calidad, perfil guerrero, posición social e influencia en la ciudad y región de procedencia, que su cantidad y que todos ellos tuvieron que ser muy bien escogidos, como ya destacó Livio al tratar específicamente acerca de los que fueron seleccionados de las ciudades de Metagonia ${ }^{94}$. Seguramente

92 Polibio aprovechó la ocasión para aclarar que baleares, cuyo nombre, propiamente, significa honderos, si bien, a partir de ese modo de usar la honda, se aplicó su nombre, por sinonimia, a los habitantes y a la isla, Plb. III 33.11.

93 Véase, por ejemplo, el análisis de los efectivos movilizados en estas campañas en Quesada 2003: 141-145.

94 Liv. XXI 21.13. 
los perfiles de estos rehenes fueron similares a las que hemos visto que tuvieron los rehenes que poco después solicitó Aníbal a aquellos pueblos de las regiones sometidas a los que reclutó para su campaña en Italia y de los que no acababa de fiarse de su lealtad. Aunque no sabemos mucho más de éstos, excepto que eran jóvenes (en edad de combatir), que estaban recluidos en la ciudadela de Sagunto y que fueron astutamente puestos en manos de los romanos en $217^{95}$. Lo que sí sabemos es que, como sirvieron también como refuerzo militar de los lugares en sus correspondientes destinos de intercambio, su perfil no tuvo nada que ver con el que años más tarde se encontró Publio, hijo, al conquistar Cartagena ${ }^{96}$. Aunque nuevamente los rehenes fueron liberados del dominio cartaginés y devueltos a sus ciudades por los romanos, con similares consecuencias en lo que respecta a la adhesión de éstas a la causa romana y a su defección de las filas cartaginesas ${ }^{97}$.

Lo que sí nos llama la atención es que la única región que contribuyó con contingentes destinados tanto a las regiones estratégicas de la provincia de Iberia como a las costeras de la provincia de Libia, fue la de los baleares. Puede ser que en esto influyera el hecho de su especialidad como honderos pero también, y seguramente, porque así Aníbal se aseguraba su lealtad a Cartago, incluso en el caso de que se perdieran los dominios de ésta en la provincia de Iberia y siempre que las islas aún no hubieran pasado a estar bajo control romano. Así como también creemos que cabe señalar que hay cuatro pueblos cuya enumeración entre los que fueron intercambiados entre las provincias de Iberia y Libia no se justifica para asegurar que, con el traslado de sus gentes al otro continente y su labor como rehenes destinados allí, se garantizara la fidelidad de su territorio o región de origen (este era el caso de los baleares, tersitas, mastianos, oretes, iberos y olcades, por una parte, así como el de los metagonitas que pasaron a Cartago, por otra, y también el de los masilios, masesilios, macceos y mauritanos). Se trata de los jinetes libiofenicios, libios e ilergetes así como de los soldados de a pie ligures y libios, pues podemos suponer que los servidores asociados a los elefantes, dadas las peculiaridades de este cuerpo de caballería más que pesada, debían ser cartagineses ya que Polibio no dijo nada acerca de su procedencia. De esos cuatro contingentes sólo uno procede de la Península Ibérica aunque, como bien señaló Pérez ${ }^{98}$, del norte del Ebro o sea de un territorio entonces conocido como Hispania, que en el invierno de 219-218 aún no estaba bajo dominio cartaginés o sea que no formaba parte de la provincia de Iberia y, por eso, tanto los cartagineses como ellos mismos se considerarían como extranjeros una vez que estuvieran al sur del Ebro. El hecho de que, después de que Aníbal cruzara al norte del Ebro, se hiciera con el control del territorio hasta los Pirineos y dejara allí un ejército a cargo del gobernador de la nueva y efímera región cartaginesa, Hannón ${ }^{99}$, así como que cuando éste se enfrentó, pocas semanas o escasos meses después, a las recién llegadas legiones romanas, le acompañara el rey de los ilergetes, como aliado de los cartagineses ${ }^{100}$, nos permite suponer que esta alianza debió de haberse alcanzado precisamente durante el invierno de 219-218 o incluso antes y que, como el resto de pueblos supeditados a los cartagineses, los ilergetes también tuvieron entonces que cumplir con su cuota de guerreros-rehenes con la estrategia defensiva de Aníbal ${ }^{101}$.

95 Plb. III 98-99 y Liv. XXII 22.4-21.

96 Plb. X 18.2-14 y Liv. XXVI 49-50.

97 Plb. X 18.3-4 y Liv. XXVI.7-14.

98 Pérez 1991: 212-213, 1994: 270 y 2003: 24.

99 Plb. III 35.4, Liv. XXI 60.5 y App. Hann. 4.

${ }^{100}$ Plb. III 76.6-7 y Liv. XXI 60.7.

${ }^{101}$ Siendo el territorio ilergete, por motivos obvios, el único al que Aníbal no destacó tropas del norte de África. Si bien, su dominio fue efectivo en cuanto cruzó el Ebro con su ejército pocos meses después. 
Los jinetes libios y libiofenicios es muy probable que, dada su condición, procedieran de las ciudades metagonitas, quizá de las más importantes de éstas ${ }^{102}$. También es muy probable que procedieran de las ciudades de la región de Metagonia los soldados de infantería libios y ligures. Éstos debieron de ser parte de los mercenarios que hubieran decidido asentarse en esta parte de Libia tras la reciente guerra de los mercenarios. De ambos pueblos hay constancia de que formaron parte de éstos, siendo el contingente libio que entonces se sublevó frente al dominio cartaginés y se unió a los mercenarios el que mayor número de personas había aportado durante esta guerra ${ }^{103}$. Por lo que asignando estos tres contingentes a la región de Metagonia y habiendo aclarado que la participación de los ilergetes se puede considerar como una avanzada de la que pronto sería la nueva y efímera región cartaginesa del norte del Ebro, se completa la descripción de la estrategia defensiva diseñada y llevada a cabo por Aníbal en el invierno de 219-218.

Quizá, antes de acabar esta revisión, convenga que recordemos que Aníbal no estuvo a cargo de la defensa de Cartago y de las regiones africanas que hemos visto que ésta tenía en la provincia de Libia. Por lo que creemos que se debe encuadrar su maniobra defensiva dentro de un plan de mayor envergadura coordinado y dirigido desde Cartago. Lo que quiere decir que para su expedición contra Roma, antes de que ésta fuera aprobada en Cartago, al igual que debieron serlo las campañas previas que emprendió casi nada más ser elegido como general del ejército cartaginés en la provincia de Iberia y para la guerra contra Roma ${ }^{104}$, Aníbal debió de convencer a su Senado de que su plan también incluía las medidas necesarias para hacerse cargo de las posibles repercusiones que éste pudiera originar en las provincias de Libia o de Iberia. Medidas que, en realidad, eran sólo el complemento a la principal acción que Aníbal tomó para asegurar la defensa de todos los dominios cartagineses: llevar la guerra a Italia y, además, hacerlo tan rápido como pudo, de modo que, como inicialmente ocurrió, se desbarataran los planes de los romanos y éstos tuvieran que replegar sus tropas, postergando los ataques previstos para ser llevados a cabo tanto en la provincia de Libia como en la de Iberia. Si bien no todos los planes de Aníbal le salieron como los había proyectado, pues la capacidad estratégica del cónsul Publio Cornelio Escipión llevó a éste a no dejarse influir por Aníbal y a mantener también a toda costa su propia estrategia y las instrucciones que al respecto le habían dado el Senado y el pueblo de Roma. Pero tampoco es este el lugar para desarrollar este tipo de comentarios ya que, en sí mismos, también han sido y deberían seguir siendo objeto de su particular estudio. Al igual que ocurre con el análisis de la escasa flota que Aníbal dejó a cargo de su hermano Asdrúbal para la defensa de la provincia de Iberia y de su precario estado, datos sobre los que hemos pasado de puntillas y sin comentarlos en esta ocasión, así como por qué ésta no reaccionó ni se unió a la defensa de la última región conquistada por

${ }^{102}$ La distinción entre libios y libiofenicios pudo deberse a que éstos no sólo eran descendientes de libios y púnicos, como señaló explícitamente Livio, Liv. XXI 22.3, sino quizá porque además vivían en ciudades que, aún siendo dependientes de Cartago, estuvieran organizadas al estilo libio y fuera de los distritos dependientes directamente de la capital, o sea, eran provincianos. Algo que ayudaría a entender el detalle que también registró Livio, al tratar acerca de las ciudades de Sicilia que aún resistían bajo dominio cartaginés en 212, cuando citó a los responsables de las tropas de éstos escribiendo: Epicides y Hannón, jefes supervivientes de la campaña anterior, y un tercero, nuevo, enviado por Aníbal para reemplazar a Hipócrates, un hipacritano de origen libiofenificio al que sus paisanos llamaban Mútines, hombre de acción que habia aprendido toda la ciencia de la guerra teniendo a Aníbal por maestro, Liv. XXV 40.5-6. Así como, unas líneas más adelante, añadió que Les sentó mal esto a los dos jefes, pero peor a Hannón, preocupado desde hacía tiempo por la fama de Mútines: éste, un medio africano, ¿le iba a poner cortapisas a él, un general cartaginés enviado por el senado y el pueblo?, Liv. XXV 40 12-13.

${ }_{103} \mathrm{Plb} . \mathrm{I} / 265$ y 67.7.

${ }^{104}$ Polibio recogió el dato acerca de que Aníbal dirigía personalmente las operaciones en Italia, a través de sus hermanos, primero con Asdrúbal y después con Magón, en Iberia, también en Sicilia, por delegación, y en Grecia e Iliria, por medio de alianzas diplomáticas, Plb. IX 22.6. 
Aníbal, en la margen izquierda del Ebro, antes de cruzar los Pirineos, cuando pocos meses después desembarcaron allí las primeras legiones romanas y se impusieron en ella con cierta facilidad. Muchas aspectos que, sin duda, tienen que ver con cómo se planeó y llevó a cabo esta estrategia defensiva de Aníbal y que quedan pendientes de su correspondiente revisión en su adecuado contexto.

\section{CONCLUSIONES}

La revisión de la información procedente de la inscripción del bronce del templo de Hera Lacinia, que registró personalmente Polibio, bajo la perspectiva de que en ella estuvo plasmada la que debió ser la estrategia defensiva de Aníbal cuando éste preparaba su expedición contra Roma, junto con la vinculación de esta información con la que también aportó de primera mano Polibio acerca de la transcripción que éste también hizo de las placas de bronce en las que se encontraban los primeros tratados entre Roma y Cartago, nos ha permitido proponer una posible distribución de las regiones cartaginesas existentes en las provincias de Libia y de Iberia, en el preámbulo de la Segunda Guerra Púnica. Lo destacado de esta hipótesis es que, además de su lógica y coherencia, está soportada por un fósil director, pues la hemos extraído a partir de los datos de una inscripción coetánea a los hechos y circunstancias narrados. Algo de lo que carece el resto de la propuesta con la que hemos intentado completar buena parte de la posible organización en regiones del dominio de Cartago en Iberia, ya que ésta procede principalmente de datos extraídos de la obra de Polibio, bien directamente o a través de otros, cuyas referencias explícitas a partes desaparecidas de ésta y de otras fuentes evitaron que su pérdida se llevara para siempre la información contenida en ellas.

Creemos que esta propuesta podría suponer un punto de inflexión en el conocimiento de los pueblos prerromanos que habitaron en la Península Ibérica antes de que comenzara la Segunda Guerra Púnica, así como un buen punto de partida también para revisar los acontecimientos que condujeron a su posterior romanización, especialmente los de la primera mitad del siglo II que son los que estaban en mayor penumbra. También creemos que contribuirá a conocer mejor la organización territorial y administrativa de Cartago antes de la citada guerra, de la que prácticamente no se sabe casi nada al haberse perdido las fuentes en las que se encontraba esta información. Así como para abundar en el conocimiento de la estrategia militar y de cómo se puso en marcha una campaña de envergadura como la que Aníbal llevó a cabo contra Roma. Siendo además un punto de partida para conocer la evolución de la etnogeografía de los pueblos prerromanos de la Península Ibérica, mucho mejor que el que hasta ahora se tenía para comprender cómo fue su posterior y largo proceso de romanización, y quizá también para saber algo más acerca de las relaciones que hubo entre ellos, en su integración bajo el consecutivo yugo cartaginés y romano, así como en sus reacciones y fallidos intentos para recuperar su libertad. Sin olvidar tampoco la contribución que este trabajo creemos que aporta para clarificar el mejor conocimiento del contenido de los primeros tratados entre Cartago y Roma, así como de las implicaciones que éstos tuvieron para ambas potencias mediterráneas y para los pueblos de la Península Ibérica. 


\section{BIBLIOGRAFÍA}

\section{FuENTES LITERARIAS CLÁSICAS: EDICIONES Y TRADUCCIONES}

Diodoro de Sicilia, Bibliotheca Historica. Diodorus of Sicily in twelve volumes, vol. III. Books IV (continued)-VIII. Cambridge, 1970: C. H. Oldfather (ed.).

Diodoro de Sicilia, Bibliotheca Historica. Diodorus of Sicily in twelve volumes, vol. X. Books XIX-XX, R. M. Geer (ed.). Cambridge, 1962.

Estrabón de Amasia, Geografía de Iberia, J. Gómez Espelosín (trad.) y G. Cruz Andreoti, M. V. García Quintela y J. Gómez Espelosín (presentaciones, notas y comentarios). Madrid, 2007.

Pline l'Ancien, Histoire Naturelle. Livre V, 1-46. L'Afrique du Nord, J. Desanges (ed.). París : 1980.

Plinio el Viejo, Natural History. Books III-VII, H. Rackham (trad.). London, 1989.

Polibio, Historias. Libro I/1, A. Díaz Tejera (ed.). Madrid, 1972.

Polibio, Historias. Libro I/2, A. Díaz Tejera (ed.). Madrid, 1982.

Polibio, Historias. Libro III, A. Díaz Tejera (ed.). Madrid, 1989.

Polibio: Historias. Libros XVI-XXXIX, M. Balasch Recort (ed.). Barcelona, 1983.

Salustio, La conjuración de Catilina. Guerra de Yugurta, A. Carrera de la Red (ed.). Tres Cantos, 2001.

Tito Livio, Ab urbe condita. Libro XXI, V. J. Herrero Llorente (ed.). Madrid, 1985.

Tito Livio, Historia de Roma desde su fundación. Libros XXI-XXV, J. A. Villar Vidal (ed.). Madrid, $1993 a$.

Tito Livio, Historia de Roma desde su fundación. Libros XXVI-XXX, J. A. Villar Vidal (ed.). Madrid, 1993 b.

Tito Livio, Historia de Roma desde su fundación. Libros XXXVI-XL, J. A. Villar Vidal (ed.). Madrid, $1993 \mathrm{c}$.

\section{EsTUDIOS}

Álvarez Martí-Aguilar, M. (2010): “Tartesios: Un etnónimo de la Iberia púnica”, Mainake, n. ${ }^{\circ}$ 32-1, 395-406.

Arasa Gil, F. (2001): “La romanització a les comarques septentrionals del litoral valencià: Poblament ibèric i importacions itàliques en els segles II-I a. C.", Servicio de Investigación Prehistórica, n. ${ }^{\circ}$ 100. Valencia.

Burillo Mozota, F. (2008): Los celtíberos. Barcelona.

Capalvo Liesa, A. (1996): Celtiberia. Zaragoza.

Ciprés Torres, Mª. P. (1999): El impacto de los celtas en la Península Ibérica según Estrabón, Estrabón e "Iberia”: Nuevas perspectivas de estudio, G. Cruz Andreotti (coord.). Málaga, 121-152.

Ciprés Torres, M. ${ }^{a}$ P. (2006): "La geografía de la guerra en Celtiberia", La invención de una geografía de la Península Ibérica. I. La época republicana, G. Cruz Andreotti, P. Le Roux y P. Moret (coord.). Madrid, 177-198.

Cruz Andreotti, G. (2002): "Iberia e iberos en las fuentes histórico-geográficas griegas: Una propuesta de análisis", 395-406, n. ${ }^{\circ}$ 24, 153-180.

Cruz Andreotti, G. (2003): Polibio y la geografía de la península Ibérica: "La construcción de un espacio político", Revisiones de Historia Antigua, Ejemplar dedicado al simposio sobre Polibio y la península Ibérica. Vitoria, 19-22 de noviembre de 2000, n. ${ }^{\circ}$ 4, Vitoria, 185-227.

Desanges, J. (1963): "Etendue et importance du Byzacium avant la création, sous Dioclétien, de la province de Byzacène", Cahiers de Tunísie, vol. XLIV, 7-22.

Desanges, J. (1990): “La localisation du 'Beau Promontoire' de Polybe”, Karthago, vol. XII, 19-31

Domínguez Monedero, J. A. (1983): "Los términos Iberia e íberos en las fuentes grecolatinas: Estudio acerca de su origen y ámbito de aplicación”, Lucentum, n. . 2, 203-224.

Domínguez Monedero, J. A. (1995): "Libios, libiofenicios, blastofenicios: Elementos púnicos y africanos en la Iberia Bárquida y sus pervivencias", Gerión, n. ${ }^{\circ} 13,223-240$.

Espada Rodríguez, J. (2013): Los dos primeros tratados romano-cartagineses. Barcelona. 
Espinosa Ruiz, U. (2004): “Crear ciudades y regir el mundo: Una síntesis sobre el papel de las colonias en la expansión territorial de Roma", Iberia, n. ${ }^{\circ}$ 7, 127-156.

Fernández Uriel, P., López Pardo, F., Gutiérrez González, R. y Benguigui Levy, S. (2001-2002): "Monedas púnicas de Rus-Addir (Melilla)", Estudios orientales, Ejemplar dedicado a II Congreso Internacional del Mundo Púnico. Cartagena, 2000, n. ${ }^{\circ}$ 5-6, 183-193.

Ferrer Albelda, E. y Bandera Romero, M ${ }^{a}$ L. de la (1997): "La localización de Mastia: Un aspecto problemático de los conocimientos geográficos antiguos sobre Iberia", Homenaje al profesor Fernándo Gascó, vol. 1. Sevilla, 65-72.

Ferrer Albelda, E. (2011-2012): "Más acá y más allá de las Columnas de Heracles. Mastia Tarseion y las limitaciones al comercio en Iberia", Cuadernos de prehistoria y arqueología. Ejemplar dedicado a: Homenaje al profesor Manuel Bendala Galán, F. Quesada Sanz, (coor.). Sevilla, n. ${ }^{\circ} 37-38,431-$ 446.

Ferrer Albelda, E. y Pliego Vázquez, R. (2013): "Cartago e Iberia antes de los Barca”, Fragor Hannibalis. Aníbal en Hispania, M. Bendala Galán (ed.). Madrid, 107-133.

Fronda, M. P. (2011): Hannibal: Tactics, strategy and geostrategy, D. Hoyos (ed.). Oxford, 242-259.

García Bellido, A. (1954): "Españoles en el norte de África durante la Edad Antigua”. Actas de I Congreso Arqueológico del Marruecos español, Tetuán, 22-26 de junio de 1953.Tetuán, 365-379.

García Moreno, L. A. (1990): "Mastienos y bastetanos: Un problema de la etnología hispana prerromana", Polis, n. ${ }^{\circ}$ 2, Sevilla, 53-65.

García-Gelabert Pérez, M. ${ }^{a}$ P. (2005): "Movilidad entre África y la península Ibérica en la Antigüedad", Hispania Antiqua, n. ${ }^{\circ}$ 29, 7-26.

Gozalbes Cravioto, E. (2000): Caput Celtiberiae. La Tierra de Cuenca en las Fuentes Clásicas. Cuenca.

Gozalbes Cravioto, E. (2010): “La romanización de Mauretania Tingitana (Marruecos)”, Espacio, tiempo y forma. Serie II, Historia Antigua, n. ${ }^{\circ} 23$. Madrid, 519-539.

Gsell, S. (1918): Historie Ancienne de l'Afrique du Nord, vol. II. París.

Hoyos, D. (2005): Hannibal's dynasty. Power and politics in the western Mediterranean, 247-183 bC. London.

Hoyos, D. (2011): "The Outbreak of War", A Companion to the Punic Wars, D. Hoyos (ed.). Oxford, 129-148.

Hoz Bravo, J. de (2010): Historia lingüística de la península Ibérica en la Antigüedad. I. Preliminares y mundo meridional prerromano. Madrid.

Kiepert, H. (1902): Atlas antiquus: Zwölf Karten zur alten Geschichte. Berlín.

Koch, M. (2003): Taršiš e Hispania. Estudios histórico-geográficos y etimológicos sobre la colonización fenicia de la península Ibérica. Madrid.

Lazenby, J. F. (1998): Hannibal's war: A military history of the Second Punic War. Oklahoma.

López Castro, J. L. (1995): Hispania poena. Los fenicios en la Hispania romana. Barcelona.

Maras, D. F. (2007): "La posizione della Sicilia nel secondo trattado romano-cartaginese", Annali della Fundazione per il Museo Claudio Faina, n. ${ }^{\circ}$ 14. Roma, 405-429.

Marcotte, D. (2006): "De l'Ibérie à la Celtique: géographie et chronographie du monde occidental avant Polybe", La invención de una geografía de la Península Ibérica. I. La época republicana, G. Cruz Andreotti, P. Le Roux y P. Moret (coord.). Madrid, 31-38.

Moret, P. (2002): "Mastia Tarseion y el problema geográfico del segundo tratado entre Cartago y Roma", Mainake. Ejemplar dedicado a Colonizadores e indígenas en la Península Ibérica, n. ${ }^{\circ} 14$, 257-276.

Moret, P. (2003): "Sobre la polisemia de los nombres Íber e Iberia en Polibio", Revisiones de Historia Antigua, Ejemplar dedicado al simposio sobre Polibio y la península Ibérica. Vitoria, 19-22 de noviembre de 2000, n. ${ }^{\circ}$ 4. Vitoria, 279-306.

Noguera Guillén, J. (2008): "Los inicios de la conquista romana de Iberia: Los campamentos de campaña del curso inferior del río Ebro", Archivo Español de Arqueología, n. ${ }^{\circ}$ 81, 31-48.

Noguera Guillén, J. (2013): Qart Hadašt, capital bárquida de Iberia, Fragor Habbibalis. Aníbal en Hispania, M. Bendala Galán (ed.). Madrid, 137-173.

Fronda, M. P. (2011): Hannibal: Tactics, strategy and geostrategy, D. Hoyos (ed.). Oxford: 242-259. 
Olcoz Yanguas, S. y Medrano Marqués, M. M. a (2011): "La expansión de los celtíberos, la conquista romana de Celtiberia y el final del estado federado de los celtíberos, en el relato de Tito Livio", Berceo. Logroño, 73-137.

Pena Gimeno, M. J. (1976-1978): “La (supuesta) cláusula referente al sudeste y al levante peninsular en el primer tratado entre Roma y Cartago", Ampurias, ejemplar dedicado a Simposi Internacional Els Origens del mon ibèric, n. ${ }^{\circ}$ 38-40, 511-530.

Pérez Almoguera, J. A. (2008): "Las monedas con nombres de étnicos del s. II a.C. en el nordeste peninsular: ¿Reflejo de posibles circunscripciones? ¿Civitates con doble nombre?”, Archivo Español de Arqueología, n. ${ }^{\circ} 81,49-73$.

Pérez Vilatela, L. (1987): "Las batallas de "Intibilis" (216-215 a. C.)", Anals de la Real Acadèmia de Cultura Valenciana, n. ${ }^{\circ}$ 65. Valencia, 171-188.

Pérez Vilatela, L. (1991): "Ilercavones, celtíberos y cartagineses en 218-217 a. C.", Caesaraugusta, n. ${ }^{\circ}$ $68,205-228$.

Pérez Vilatela, L. (1994): “Onus(s)a: Toponimia y comercio antiguos en el litoral del Maestrazgo", Polis, n. ${ }^{\circ}$ 6. Sevilla, 269-306.

Pérez Vilatela, L. (2000): Lusitania. Madrid.

Pérez Vilatela, L. (2003): "Polibio (III, 33, 9 s.) y la administración territorial cartaginesa de Iberia", Hispania Antiqua, n. ${ }^{\circ}$ 27, 7-42.

Picard, G. C. (1966): "L'administration territoriale de Carthage”, Mélanges d'archéologie et d'histoire offerts à André Piganiol, R. Chevalier (ed.), vol. 3, Paris, 1257-1265.

Prados Martínez, F. (2008): Arquitectura púnica: Los monumentos funerarios, Anejos de Archivo Español de Arqueología, n. ${ }^{\circ}$ 44. Madrid.

Quesada Sanz, F. (2003): "La Guerra en las comunidades ibéricas (c. 237-c. 195 a. C.): Un modelo representativo", Defensa y territorio en Hispania de los Escipiones a Augusto: (Espacios urbanos y rurales, municipales y provinciales). Coloquio celebrado en la Casa de Velázquez (19 y 20 de marzo de 2001), A. Morillo Cerdán, F. Cadiou y D. Hourcade (coord.). Madrid, 101-158.

Salinas de Frías, M. (2006): Los pueblos prerromanos de la península Ibérica. Tres Cantos.

Sancho Royo, A. (1976): "En torno al tratado del Ebro entre Roma y Asdrúbal", Habis, n. ${ }^{\text {o 7, 75-110. }}$

Santos Velasco, J. A. (1983): "La denominada necrópolis ibérica de Orán, en el Museo Arqueológico Nacional", Trabajos de Prehistoria, n. ${ }^{\circ}$ 40. Madrid, 309-352.

Scardigli, B. (2011): "Early Relations between Rome and Carthage", A Companion to the Punic Wars, D. Hoyos (ed.). Oxford, 28-38.

Schulten, A. y Bosch Gimpera, P. (1935): Las guerras de 237-154 a. de J.C. Fontes Hispaniae Antiquae, A. M. Trepat Piera y E. Valentí Fiol (trad.), v. 3, (FHA III). Barcelona.

Tovar Llorente, A. (1989): Iberische Landeskunde. II. Las tribus y las ciudades de la Antigua Hispania. 3. Tarraconensis, Baden-Baden.

Recibido: 22/05/2013

Aceptado:12/06/2014 